\title{
Proceedings of the British Cardiac Society and Swedish Society of Cardiology
}

A Joint Meeting of the British Cardiac Society and the Swedish Society of Cardiology was held at Imperial College, London, on Thursday and Friday, 24 and 25 November 1977. Chairmen: B. Johansson and A. Leatham. The Young Research Workers Prize was won by A. Raine, the other finalists being Nina Rehnqvist, D. Russell, and J. Lessem. A. Maseri delivered the Thomas Lewis Lecture on 'A study of pathogenic mechanisms of angina pectoris at rest'. The subject of the plenary session was 'Angina pectoris-when to investigate and when to operate'. Speakers in this session were D. Julian, D. Ross, and D. Chamberlain. In addition to the scientific sessions there were six lunch-time teaching panels; abstracts of these and of the scientific sessions follow.

\section{Angina pectoris-when to investigate}

D. G. Julian

Newcastle General Hospital

Specialised investigations may be required to (1) demonstrate myocardial ischaemia, (2) establish causation, (3) assess overall and regional myocardial function, (4) estimate prognosis, and (5) delineate arterial anatomy before surgery.

Stress electrocardiography is, by itself, a relatively insensitive and non-specific tool for these purposes. However, if it is accompanied by simultaneous observations of changes in heart rate and blood pressure, it may provide valuable evidence of ischaemia and myocardial malfunction and should be a routine investigation in all but the elderly patient.

Radionuclide stress testing is an effective way of showing the presence and location of ischaemic areas. Expense precludes its widespread application, but its use is particularly justified in patients with suspected angina without electrocardiographic abnormalities and in asymptomatic individuals with abnormal electrocardiographic stress tests.

Coronary arteriography is a sensitive test for advanced coronary atherosclerosis and arterial spasm but has a still undetermined specificity for ischaemic heart disease. Even when combined with ventriculography, it is not a reliable diagnostic tool for angina. It provides useful prognostic in- formation but this is not a sufficient reason for undertaking it. The main indication for this investigation is to define the arterial anatomy in those patients for whom surgery is contemplated.

\section{Results of surgery}

Donald Ross

National Heart Hospital and Guy's Hospital and the Institute of Cardiology

In the 10 years since the introduction of coronary angiography combined with saphenous vein bypass surgery, the incidence of coronary artery disease has risen to the point where it is the major cause of death in western society especially in the USA where there are an estimated 15 million cases and 700000 deaths annually. During this time surgery has become an increasingly popular form of treatment and figures suggest that about 30000 of these operations are carried out annually in the USA.

Enthusiasm for this form of surgery has been much more slowly kindled in this country and Europe and cardiological opinion is still somewhat reserved in its indications for coronary angiography as a prelude to possible surgery. There is, however, evidence of an increasing number of vein bypass operations being carried out in the United Kingdom though we are still behind countries like Australia in terms of percentage of the population treated.

It is appropriate and timely to try to make some objective assessment of what surgery achieves in terms of rehabilitating patients, relieving symptoms, improving functional capacity, and increasing life expectancy. We need to know about the ill effects of the operation. Some fairly hard facts have been established particularly with regard to surgical mortality, relief of symptoms, and patency of the grafts and the incidence of perioperative infarcts. More controversy and doubt centres on the prospects of increased life expectancy, improvement in ventricular function, and the prevention of further infarcts while relatively little is known about the long-term prospects for these grafts and their influence on the native circulation.

Significantly the accumulating evidence indicates that surgery has little to offer in isolated single vessel disease unless this is in the left main coronary 
artery but most authorities are agreed that double and triple vessel disease has a better outlook treated surgically than medically.

The emergency use of surgery in acute myocardial ischaemia is no longer pursued with as much enthusiasm or vigour and in this respect the intraaortic balloon pump probably plays a useful part.

At the same time the attitude to unstable angina has also undergone a change with more attention to medical management and later elective surgery.

The surgical treatment of the complications of an infarct like aneurysm, ventricular septal defect, and mitral regurgitation seems to be well established and is usually combined with appropriate saphenous vein bypass. Even more common is the combination of aortic valve surgery with this procedure.

\section{Treatment of the non-surgical case}

\section{A. Chamberlain}

\section{The Royal Sussex County Hospital, Brighton}

Concepts of the pathophysiology of angina have widened with the advent of coronary angiography and scintigraphy, and with advances in medical and surgical therapy. The anatomy of the coronary circulation is inconstant and some variants may predispose to localised circulatory insufficiency. Flow can be impaired both by obstruction and by spasm, and small vessel and metabolic abnormalities may also engender ischaemia. Surgical treatment is appropriate for most cases with stable symptomatic obstructive disease, but drug therapy remains the mainstay not only for patients with inoperable lesions and poor myocardial function but also for those with angina in the presence of non-atheromatous vessels. Satisfactory results in these groups often demand concurrent treatment with drugs of different types including nitrites of old or more recent formulation, beta adrenoceptor antagonists, and newer antianginal agents which may work in part by influencing coronary arterial tone or spasm.

\section{Baroreceptor resetting in unmyelinated nerve fibres arising from aortic arches of hypertensive rabbits}

J. V. Jones and P. N. Thoren

Department of Cardiovascular Medicine, Radcliffe Infirmary, Oxford, and Department of Physiology, University of Gothenburg, Sweden

Myelinated fibres arising from the baroreceptor regions have been shown to reset to operate around the higher blood pressure in hypertension. Recently small unmyelinated fibres arising from these regions. in normotensive animals have been described. They were thought to have higher thresholds than myelinated fibres and to be primarily antihypertensive in character. In view of this some characteristics of unmyelinated fibres arising from the aortic arches of hypertensive rabbits were studied.

Rabbits were made hypertensive by unilateral renal artery clipping followed later by contralateral nephrectomy. They were then left for a further 6 to 8 weeks before being used in a study. Fifty-four medullated fibres and 47 non-medullated were studied. As occurs in normotensive animals the non-medullated fibres had higher thresholds and lower discharge frequencies than did the medullated fibres. Though the unmyelinated fibres had reset in chronic hypertension they were less reset than the myelinated aortic baroreceptors from the same animal. Thus unmyelinated fibres may have a role to play in the tonic control of the circulation in chronic hypertension.

\section{Effects of treatment on pressor responses to exertion in hypertensive patients}

S. H. Taylor, S. J. Watt, and P. W. Goldstraw University Department of Cardiovascular Studies and Department of Medical Cardiology, The General Infirmary, Leeds

Cardiovascular morbidity in hypertensive patients is directly related to the height of the systolic blood pressure (Kannel and Dawber, 1974); the correlation is closer if the effects of exertion are taken into account (Sokolow et al., 1966). Different types of exertion produce different pressor effects in hypertensive patients (Taylor, 1975), but the comparative effects of treatment on these pressor responses remain to be described.

Twelve male patients aged 38 to 55 years with uncomplicated essential hypertension were studied after two months' treatment in a double-blind randomised cross-over study with placebo and each of the following drugs: hydrochlorothiazide $50 \mathrm{mg}$ b.d., oxprenolol $160 \mathrm{mg}$ b.d., bethanidine $20 \mathrm{mg}$ b.d., methyldopa $500 \mathrm{mg}$ b.d., and clonidine $0.3 \mathrm{mg}$ b.d. At the end of each 8-week period measurements of heart rate and blood pressure were made supine, standing, during dynamic exercise (treadmill walking), and during isometric exertion (handgrip contraction).

All drugs produced a lowering of the supine and standing systolic and diastolic pressures. The 
systolic pressor response to walking after placebo $(+38 \mathrm{mmHg})$ was significantly reduced only after oxprenolol and bethanidine; the diastolic decrease $(-7 \mathrm{mmHg})$ was unchanged after all drugs. Exercise tachycardia was reduced only after oxprenolol and bethanidine. The systolic pressor response to isometric exercise $(+37 \mathrm{mmHg})$ was unchanged after all drugs, but the diastolic increase after placebo (+38 $\mathrm{mmHg}$ ) was significantly reduced after hydrochlorothiazide, bethanidine, methyldopa and clonidine. The tachycardia associated with handgrip was reduced only after oxprenolol and bethanidine.

It is concluded that drugs which block cardiac adrenergic transmission or cardiac beta-adrenoceptors are most effective in attenuating the pressor and tachycardia response to dynamic exertion; none of the drugs tested reduced the systolic pressor increase during isometric exercise. Vascular protection against the increased mechanical forces of systolic pressure and heart rate during dynamic exercise appears to be achieved only by drugs that block cardiac sympathetic stimulation.

References

Kannel, W. B., and Dawber, T. W. (1974). Hypertension as an ingredient of a cardiovascular risk profile. British fournal of Hospital Medicine, 2, 508.

Sokolow, M., Werdegar, D., Kain, H. K., Hinman, A. T. (1966). Relationship between level of blood pressure measured casually and by portable recorders and severity of complications in essential hypertension. Circulation, 34, 279.

Taylor, S. H. (1975). The circulation in hypertension. In Hypertension-Its Nature and Treatment, Ed. D. M. Burley, Ciba Laboratories, Horsham, England.

\section{Unbiased blood pressure measurement by cuff and stethoscope. \\ Report on methodology and effects of $\beta$-blockers, labetalol, glyceryl trinitrate, and atropine on heart rate and blood pressure at rest and during sustained handgrip}

\section{G. Nyberg}

Medical Department I, Sahlgrenska Hospital, S-413 45 Göteborg, Sweden

Isometric contraction of a muscle group at more than 15 per cent of maximal voluntary contraction (MVC) produces a reflex increase in systolic and diastolic blood pressure and heart rate, linear with time. The blood pressure response results mainly from increased sympathetic tone and the heart rate response mainly from withdrawal of vagal tone. A method of indirect recording of these responses, validated against intraarterial measurements, which wholly eliminates observer bias, is described. An electronic development of the London School of Hygiene sphygmomanometer, the Auto-Manometer ${ }^{\otimes}$, is used so that recordings can be made at one-minute intervals.

Subjects have been studied at rest and during handgrip ( $50 \%$ of $\mathrm{MVC}$ ). At one minute of handgrip, normotensives increased by 22 to $30 \mathrm{mmHg}$ systolic, 17 to $32 \mathrm{mmHg}$ diastolic, and 17 to 21 heart beats/min. Hypertensives increased by 32 to $42 \mathrm{mmHg}$ systolic, 23 to $30 \mathrm{mmHg}$ diastolic and 11 to 20 heart beats/minute.

Selective and non-selective $\beta$-blockers attenuated the heart rate response but not the blood pressure rise. However, in a cross-over comparison of metoprolol $400 \mathrm{mg} /$ day and propranolol $320 \mathrm{mg} /$ day, diastolic blood pressure rose significantly less after metoprolol. A combination of $\beta$-blocker, vasodilator, and clonidine also attenuated the blood pressure rise, both systolic and diastolic, as did labetalol, an $\alpha$ - and $\beta$-blocker. Sublingual glyceryl trinitrate and intravenous atropine both attenuated the systolic blood pressure rise, but not the increase in heart rate, though heart rate level was raised.

\section{Circadian rhythm of blood pressure in untreated hypertensive patients}

M. W. Millar Craig, E. B. Raftery, and C. Bishop Northwick Park Hospital and Clinical Research Centre, Harrow, Middx.

Arterial blood pressure and heart rate have been recorded continuously over 24-hour periods in 20 untreated ambulant outpatients with essential hypertension and in 5 normal individuals, using the Oxford intra-arterial recording system. The data were analysed by obtaining mean values for systolic blood pressure, diastolic blood pressure, and heart rate for each hour of each day using a specially developed computer programme. The curves obtained showed that contrary to popular belief, in hypertensive subjects, blood pressure and heart rate are maximal in the morning $(0900 \mathrm{~h}$ to $1200 \mathrm{~h})$ and then fall steadily throughout the day to reach a nadir at $0300 \mathrm{~h}$. Blood pressure begins to rise again at $0500 \mathrm{~h}$ to reach high levels by $0900 \mathrm{~h}$. This initial increase in blood pressure was not associated with physical activity. A similar increase in heart rate occurred, but this did not begin until $0700 \mathrm{~h}$. A similar pattern of blood pressure and heart rate was seen in the normotensive individuals. These observations suggest a correlation between the early morning rise in blood pressure and a common time of onset of stroke and myocardial infarction, which has important therapeutic implications. 
Panel A: Current approaches to management of
myocardial infarction

Introduction

\section{B. L. Pentecost}

General Hospital, Birmingham

The clinical management of myocardial infarction remains fundamentally concerned with the correction and prevention of the arrhythmias. The treatment of myocardial pump failure remains disappointing. Established cardiac shock is associated with extensive myocardial injury and therefore much current research is directed towards limiting the extent of myocardial damage. Theoretically, this could be achieved by reducing myocardial oxygen demand of ischaemic but potentially viable myocardium by the correction of tachyarrhythmias or through the use of beta-adrenoceptor blocking drugs. There have been encouraging studies both clinical and experimental to suggest that betablocking drugs may reduce analgesic requirement and modify the extent of myocardial injury, but there have been few controlled clinical observations. One prospective controlled study has shown no benefit to derive from the routine use of betablockers in the acute stages of haemodynamically mild infarction where the early and late incidence of shock and cardiac failure are used as indices of myocardial damage. It seems likely that any procedure which lowers systemic blood pressure and heart rate will be beneficial to some patients through reduction in myocardial oxygen demand, but hazardous to others as a result of the fall in coronary perfusion pressure. Attempts to modify metabolic substrate utilisation by the myocardium in order to mitigate the effects of hypoxia is possibly a more promising approach.

\section{Antiarrhythmic drugs and pacemaker therapy}

\section{Mogensen}

St. Eriks Sjukhus, 11283 Stockholm, Sweden

A review of studies on antiarrhythmic treatment in the CCU setting are presented. The concepts of warning arrhythmias and prophylactic therapy are critically questioned. Commonly used drugs for elective antiarrhythmic treatment are discussed, and the treatment of conduction defects outlined.

\section{Rehabilitation}

\section{Peter Carson \\ City General Hospital, Stoke-on-Trent}

Fear and depression are the commonest complications of myocardial infarction and common reasons for failing to return to a normal and active life. The shorter the period of rest after the acute episode the less the deterioration there is in physical working capacity and in morale.

In the CCU, daytime bed rest in those free from shock, heart failure, and persisting pain is used on the first day only, and most patients are walking on the fifth hospital day. Seventy-six per cent of survivors were discharged by the 8th hospital day.

Since 1972, we have been running an exercise programme for men who have survived infarction, the first year being a feasibility study, and since then, an ongoing controlled trial. Patients under the age of 70 who are free from obvious contraindications (to be discussed) are randomly selected into exercise and control groups 6 weeks after discharge from hospital. The exercise group attend the gymnasium for medically supervised sessions twice weekly for 3 months. The improvement in physical fitness is highly significant, and in morale obvious. About one-third of the total number of patients admitted and about one-half of the survivors 6 weeks after discharge fulfil our criteria for a strenuous exercise course which is safe, enjoyable, and beneficial.

\section{Panel B : Echocardiography-its diagnostic value in a district general hospital}

\section{Equipment}

D. Gibson

\section{Echocardiography in a district general hospital}

\author{
J. D. Whiteside and D. Gillmer \\ Chichester District (Royal West Sussex) Hospital
}

Echocardiography is a valuable and safe investigation and is inexpensive to install. A good diagnostic service can be run without additional staff, but does require training and experience. It is particularly useful in the absence of a catheter laboratory and will improve the selection of patients being referred 
for more costly investigations in a cardiac centre. It widens the understanding of cardiac physiology and pathology by all levels of staff.

The most common requests for echocardiography are in the diagnosis of murmurs or the more accurate assessment of large hearts.

Congestive heart failure and cardiomegaly are very common, especially in the elderly. Echocardiography effectively excludes a correctable lesion, such as pericardial effusion and unsuspected valvular lesions. A confident diagnosis of congestive cardiomyopathy is rapidly made though aetiological diagnosis must depend on clinical evidence. It is particularly in this field that unnecessary cardiac referrals are reduced. Hearts diffusely damaged by ischaemic heart disease can be recognised and improved techniques and digitisation may differentiate those with localised akinesia, which may benefit from surgery.

In our opinion, echocardiography, like electrocardiography and radiology, is a clinical investigation and should be available in every district general hospital.

\section{Valvular disease}

\section{G. C. Sutton \\ Hillingdon Hospital}

The principal problems in the assessment of valve disease are to confirm the diagnosis, to estimate severity, and to detect additional factors such as left ventricular dysfunction, coronary artery disease, or infective endocarditis. Though echocardiography cannot provide precise information about coronary artery disease or regional abnormalities of left ventricular contraction, it can make the diagnosis and assess the severity of valve lesions, estimate overall left ventricular performance, and aid the diagnosis of infective endocarditis. Rheumatic mitral valve disease, posterior mitral cusp prolapse, and aortic regurgitation are diagnosed from the appearance of the mitral leaflet echoes. The severity of mitral or aortic regurgitation is determined by calculating left ventricular stroke volume from left ventricular dimensions. Ejection fraction derived from left ventricular dimensions enables mitral regurgitation, the most frequent valvular abnormality in a general hospital, to be separated into primary or secondary to left ventricular dysfunction. Vegetations may be recognised in infective endocarditis, and the development of severe aortic regurgitation by finding premature mitral valve closure.
Echocardiography in conjunction with other noninvasive techniques may eliminate the need for diagnostic cardiac catheterisation in many patients with valve disease, referral to the cardiac centre being reserved for surgical treatment.

\section{Panel C: Value of electrophysiological studies in management of arrhythmias}

\section{Value of electrophysiological studies}

D. M. Krikler

Royal Postgraduate Medical School, Hammersmith Hospital, London

At present, these studies have their greatest value in the investigation of reciprocating atrioventricular arrhythmias, not only for confirmation of the diagnosis and demonstration of the mechanism, but also for assessment of therapeutic response. It still remains to be shown that extrapolation from such acute interventions gives a precise guide to subsequent oral prophylaxis. In many ways the greatest value of the studies discussed, for the general physician and for the cardiologist who does not have direct access to them, is the lessons that can be derived for the better clinical and electrocardiographic analysis of rhythm and conduction disturbances. Such studies are also an essential feature of the assessment of cases in whom surgical operation is being considered, e.g. for intractable arrhythmias complicating the Wolff-Parkinson-White syndrome, and in the management of intractable ventricular tachycardias. In all cases subjected to study, it is vital that the maximum information be acquired at that time. This means the use of an appropriate number of intracardiac leads so that stimulation and recording can be carried out from both the atrium and the ventricle, and, wherever possible, left atrial recordings made. Unless this principle is observed, inadequate information may lead to highly erroneous conclusions.

\section{Tachycardias-role of clinical cardiac electrophysiological techniques}

\section{A. J. Camm \\ St. Bartholomew's Hospital, London EC1}

The majority of paroxysmal, regular tachycardias have a re-entrant mechanism. These tachycardias are initiated by suitably timed premature beats which conduct down only one of two possible pathways and return to the point of stimulation via the 
unused pathway. The tachycardia is maintained by the continuous circulation of the impulse in the reentrant pathway until its physiological properties change or it is interrupted by another premature beat. These characteristics allow detailed study of such tachycardias in the cardiac laboratory.

The sequence of cardiac activation may be studied by the use of multiple intracardiac electrodes which register only local activity. The time of activation of each signal may be used to construct the direction of depolarisation during both sinus rhythm and tachycardia. In order to study any tachycardia adequately, electrodes must be positioned to record activity from the high right atrium, the His bundle, and the left atrium.

The principles of tachycardia analysis may be illustrated by considering atrioventricular junctional tachycardias which are recognised on the surface electrocardiogram by regular, normal QRS complexes and inverted $P$ waves in inferior leads. There are several different tachycardia circuits which may produce this electrocardiographic appearance. In all cases anterograde conduction utilises the atrioventricular node and His bundle, but the impulse may return to the atrium via a second atrioventricular nodal pathway, an anomalous atriojunctional fibre, or a direct atrioventricular connection. The conditions required for the initiation of tachycardia, the earliest atrial activation during tachycardia and the mechanism of tachycardia termination together provide the information needed to differentiate these circuits and allow suitable therapy to be designed.

\section{Conduction defects}

\section{T. R. Evans}

Hammersmith Hospital, Royal Postgraduate Medical School

Intracardiac electrography has contributed to understanding the mechanism, defining the level, and rational therapy in atrioventricular blocks. Three levels of atrioventricular blocks are recognised (1) supraHisian, (2) intraHisian, (3) infraHisian; determination of the level of the block is of value in assessing the need for permanent pacemaker implantation. In the asymptomatic patient the recognition of a bifascicular intraventricular conduction block on the surface electrocardiogram gives rise to concern. Normal or minimally lengthened HV times usually exclude the need for a permanent pacemaker therapy. Current consensus suggests that the patients with bifascicular block and a much prolonged $\mathrm{HV}$ time (indicating disease of the remaining fascicle) should be considered for pacemaker implantation. Pacing studies, aimed at stressing atrioventricular conduction, have not been consistently reliable.

In sinoatrial disease, intracardiac electrography has been of less value. Corrected sinus node recovery time after rapid atrial pacing has proved to be the single most useful indicator of clinically significant sinoatrial disease. Sinoatrial conduction time measured by premature atrial stimulation has been extensively studied, but, while sometimes able to detect early disease, it has failed to establish itself in routine clinical practice because it is likely to give meaningful results in only 50 per cent of all patients and in very few with severe sinoatrial disease.

\section{Electrocardiographic signs and creatine kinase release in patients on beta-blockers suffering acute myocardial infarction}

K. M. Fox, A. P. Selwyn, E. Welman, A. Jonathan, and J. P. Shillingford Cardiovascular Research Unit, Royal Postgraduate Medical School, Hammersmith Hospital, Du Cane Road, London W12 0HS

The electrocardiographic signs of ST segment elevation and development of $Q$ waves using 72-lead praecordial surface mapping and the release of creatine kinase $(\mathrm{CK})$ activity has been studied in 9 patients on beta-blockade therapy suffering acute anterior myocardial infarction. Forty-seven patients with uncomplicated anterior myocardial infarction acted as controls. It was found that beta-blockers suppressed the natural history of ST segment changes but had no effect on the pattern and time course of the loss of electrically active myocardium. A relation was found between the area of ST segment elevation at 2 to 3 hours and the final development of $Q$ waves in the control patients $(\mathrm{P}<0.001, \mathrm{r}=0.88, \mathrm{n}=33$ ) but not in the patients on beta-blockers. The pattern of changes in plasma $\mathrm{CK}$ and $\mathrm{MBCK}$ activity was similar in both groups.

These findings suggest that established betablockade has not altered the loss of viable myocardial tissue after acute myocardial infarction. Furthermore the technique of praecordial surface mapping cannot be used to define the salvage of myocardium in this clinical situation. 


\section{Rapid lysis of coronary thrombi}

\author{
H. A. Dewar, R. H. Smith, and P. M. Hacking \\ Royal Victoria Infirmary, Newcastle upon Tyne
}

A small number of patients with acute myocardial infarcts of less than 12 hours' duration have received a 3-hour systemic infusion of plasminogen, some of which it is assumed will be absorbed by the thrombus in the relevant coronary artery. Subcutaneous heparin is also given to discourage spread of the thrombus. Coronary arteriography is then done to show the site of the occlusion and a small amount of streptokinase is infused through the Judkin catheter for $\mathbf{3 0}$ to $\mathbf{4 0}$ minutes. The arteriogram has been repeated at 10-minute intervals and the gradual but incomplete return of circulation will be shown in slides and in a short cine film. There have been no ill effects, and since systemic fibrinolysis was avoided, there has been no excess bleeding from the femoral artery puncture.

Infarcts have not been prevented and both the potential and some of the limitations of the treatment will be described.

Antihypertensive and antiarrhythmic effects of beta-adrenergic blockers in patients on long-term therapy

\section{A. E. G. Raine \\ Cardiac Department, The Radcliffe Infirmary, Oxford}

Despite the wide clinical use of beta-adrenergic blocking drugs, their therapeutic mode of action is not fully understood. In animals long-term betablockade has been shown to reduce sympathetic activity and prolong cardiac repolarisation time, effects which are not seen acutely. The present study concerns the effects of both acute and longterm beta-blockade on these functions in man.

Two groups of patients were investigated, 21 receiving long-term treatment with beta-adrenoceptor antagonists and 22 matched controls. The effects of acute beta-blockade in 6 volunteers and three weeks' treatment in 5 patients were also compared.

In these studies acute beta-adrenergic blockade with propranolol $(10 \mathrm{mg}$ i.v.) reduced heart rate but had no effect on mean blood pressure, electrocardiographic QT interval duration, or the rise in plasma noradrenaline concentration and dopamine$\beta$-hydroxylase (DBH) activity after treadmill exercise. In contrast after long-term beta-blockade both heart rate and blood pressure were reduced, the increases in plasma noradrenaline and $\mathrm{DBH}$ after exercise were significantly diminished, and the QT interval was lengthened.

It is concluded that long-term administration of beta-adrenergic blockers reduces sympathetic nervous activity and increases myocardial repolarisation time in man, as in animals. These actions may contribute to the hypotensive and antiarrhythmic effects of long-term beta-blockade.

\section{Ventricular arrhythmias after acute myocardial infarction, prognostic weight, and natural history 1}

\section{Nina Rehnqvist \\ Serafimer Hospital, \\ S-112 83 Stockholm}

One hundred and sixty consecutive CCU-treated patients with acute myocardial infarction below 66 years were investigated for ventricular ectopic beats (VEB) by 6-hour telemetry before discharge and after one year. During the first year of followup 11 patients died suddenly and 20 suffered reinfarction. Three independent prognostic parameters for the first year of follow-up were found: (1) radiological heart enlargement; (2) severe VEBs before discharge; (3) diabetes mellitus. Severe VEBs were more common in male patients in those of above median age, with a previous cardiac history, a large infarct, a transmural infarct, ventricular tachycardia or ventricular fibrillation in CCU or radiological cardiomegaly. VEB severity increased in 43 per cent of the 122 survivors without reinfarction, who were reinvestigated, and decreased in 27 per cent. Deterioration was seen primarily in older male patients with a previous cardiac history. During the second year of follow-up 13 patients suffered reinfarction or died suddenly. Ten $(77 \%)$ showed severe VEBs one year after the acute myocardial infarct in contrast to 43 per cent of patients without these complications. Severe VEBs before discharge were found to carry prognostic weight for the first and the first plus the second year of follow-up but not for the second year per se.

'This study was supported by the Swedish National Association against Heart and Lung Diseases. 


\section{Efiect of glucose on pathogenesis of early ventricular arrhythmias during acute myocardial ischaemia}

\author{
D. C. Russell \\ Department of Cardiology, Royal Infirmary, \\ Edinburgh
}

An early phase of malignant ventricular arrhythmias occurs soon after experimental coronary occlusion and probably relates to the high incidence of sudden death in man within the first hour of ischaemia.

A technique has been developed for the combined measurement of intracellular and extracellular potentials, metabolic gradients (arterial-local coronary venous differences) and regional myocardial blood flow after acute left anterior descending coronary occlusion in the dog in order to examine the pathogenesis of these arrhythmias and the influence of glucose administration.

Ventricular fibrillation (VF) resulting within successive 5-minute occlusion periods was preceded by increased endocardial-epicardial conduction delay (CD) and action potential (AP) shortening, alternans, and conduction block. 'Slow response' type potentials occurred. Effects were more severe at higher heart rates and during initial occlusions.

Glucose administration (arterial levels 12.5士 $1.2 \mathrm{mM}$ ) after high coronary occlusion transiently reduced $\mathrm{AP}$ and $\mathrm{CD}$ change but had no effect on incidence of VF. Significant improvements in AP and $C D$, however, occurred during more moderate ischaemia and were associated with increased arterial-local venous differences of glucose.

It is suggested that increased availability of glucose protects against early ventricular arrhythmias in mild or moderate but not severe myocardial ischaemia.

\section{Myocardial scintigraphy with ${ }^{99} \mathrm{~m}$ Tc- (stannous) pyrophosphate in rats with experimentally induced myocardial infarction}

Jan Lessem (in collaboration with Ernest Page, Philip Polimeni, Leon Resnekov, and Paul Harper)

University of Chicago, Department of Medicine, Chicago, Illinois, USA

Rats were imaged with Tc-99m pyrophosphate after production of left ventricular infarcts by in vivo ligation of the anterior coronary artery, using a gamma camera with a $1 \mathrm{~mm}$ pinhole collimator at a magnification of 5 to 1 . The hearts were initially imaged 4 hours after ligation and then daily for the next 3 days. Hearts from a second group of rats were imaged ex vivo, after which infarcted and noninfarcted tissues were assayed for radioactivity in a well-type gamma counter. A third group of rats with myocardial infarctions was sacrificed at the same number of hours after ligation for a histological study. The infarcts were detected by the technetium scanning technique within 4 hours, rose in intensity to a maximum at the 24 and 48 hours intervals, and had declined to low values by 72 hours. The ratio of activity between infarcted and border zone was at peak during $\mathbf{4 8}$ hours after ligation. During the 2-day period of maximum intensity the intensity in the infarcted zone was 12 to 77 times greater than that in tissue remote from the infarct, while the corresponding radioactivities ranged from 17- to 75-fold greater. When light micrographs were correlated fuchsinophilia was shown in infarcted areas 4 hours after ligation, and nearly complete removal of necrotic myocardial cells was shown by phagocytes 72 hours after ligation. It can thus be concluded that the image reflects predominantly the $T c$ content of myocardial cells which are irreversibly damaged or already programmed to die.

\section{Three-dimensional animation of spread of excitation of human heart}

F. L. Meijler, K. Moldenhauer, A. van Oosterom, P. Heintzen and D. Durrer

Interuniversity Cardiological Institute,

The Netherlands. Christian-Albrechts

University, Kiel, Federal Republic of Germany

A three-dimensional animation of the spread of excitation through the heart has been generated with the aid of a digital computer. Excitation data were obtained by epicardial and intramural exploration in an isolated revived human heart.

The results are presented in the form of successive excitation boundaries at $5 \mathrm{~ms}$ intervals in 8 equidistant slices of the heart. The animation shows a perspective view of the heart composed of the 8 layers which were used as a frame for the dynamic display of the excitation process. The spread of excitation is shown in 12 successive $5 \mathrm{~ms}$ steps of colour changes on a colour movie film taken from a colour television screen interfaced to the computer. Anterior and posterior views of the heart are shown in 2 different slow motion representations. This form of data display offers a spatial and dynamic representation of the spread of normal excitation of a 'normal' human heart. The visualisation of abnormal excitation patterns such as occurring in 
hearts with infarcted areas, intramural conduction defects, ventricular premature beats, and preexcitation syndromes, is the goal of future studies.

\section{QT time in congenital complete heart block}

Eva Esscher and Magnus Michaëlsson

Akademiska Sjukhuset, Uppsala, Sweden

The study includes 273 cases of congenital complete heart block where at least one electrocardiogram was available and it was possible to calculate the QT time. The QT time was corrected for heart rate and a corrected QT time of more than 0.43 was said to be prolonged. The QT time was correlated with the presence of associated cardiovascular malformations, sudden death, Adams-Stokes seizures, and other symptoms leading to pacemaker treatment.

\begin{tabular}{|c|c|c|c|c|}
\hline Cases with no associa & $\begin{array}{l}\text { ated heart } \\
\text { Normal } \\
Q T_{\mathrm{c}}\end{array}$ & $\begin{array}{l}\text { isease } \\
P \text { Prolonged } \\
Q T_{\mathrm{c}}\end{array}$ & $\begin{array}{l}\text { Cases wit } \\
\text { Normal } \\
Q T_{\mathrm{c}}\end{array}$ & $\begin{array}{l}\text { heart disease } \\
\text { Prolonged } \\
Q T_{\mathrm{c}}\end{array}$ \\
\hline $\begin{array}{l}\text { Total no. of cases } \\
\text { No. with symptoms }\end{array}$ & $\begin{array}{r}161 \\
16\end{array}$ & $\begin{array}{l}37 \\
31\end{array}$ & $\begin{array}{l}53 \\
16\end{array}$ & $\begin{array}{l}22 \\
19\end{array}$ \\
\hline
\end{tabular}

The table shows that symptoms occur in cases with normal as well as prolonged QT time but also that symptoms are more frequent in the groups with prolonged QT time. The electrocardiograms were made at highly varying periods of time in relation to the symptoms. It has earlier been believed that a prolonged QT time is a finding coinciding with an Adams-Stokes attack. In no less than 21 cases prolonged QT time preceded the symptoms. The median period of time between the electrocardiogram and symptoms was 5 months (range 14 days to 4 years). Thus prolongation of QT time might be added as one of the risk factors in predicting symptoms in congenital heart block.

\section{Evaluation of computer programme for 12-lead electrocardiographic interpretation}

Johan Landelius and Lars Nordgren Akademiska Sjukhuset, Uppsala, Sweden

A 12-lead electrocardiogram interpretation computer programme is available commercially from Cardionics, Brussels, Belgium. The programme performance was tested on an ordinary hospital population by a method allowing the clinician to judge the usefulness of the programme for his specific setting and needs. When applied to the Cardionics programme experienced electrocardiogram readers found essential agreement with the programme result in 83.5 per cent of 493 nonselected tracings. Clinically significant disagreements based on application of different criteria occurred in 6.0 per cent of the tracings, whereas disagreements based on programme errors were found in 10.5 per cent of the tracings.

Appropriate statistics used in this type of investigation are discussed.

Spontaneous reversion from year-long atrial fibrillation to sinus rhythm

S. Bertil Olsson, G. Örndahl, and S. Eneström Department of Cardiology, Med Clin I, Sahlgrenska Sjukhuset, Göteborg, Sweden

There are less than 20 documented cases of atrial fibrillation of 2 years' duration with spontaneous reversion to sinus rhythm. We have collected 10 additional cases with atrial fibrillation of 3 to 17 years' duration and with spontaneous reversion to sinus rhythm.

Of our 10 patients, 9 had significant rheumatic mitral valve disease.

Several of our patients spent up to a year with different atrial arrhythmias before sinus rhythm was established.

In most patients the electrocardiogram shows first degree AV block after return to sinus rhythm and has a low-amplitude $P$ wave-as if the left atrial $\mathbf{P}$ component were lacking.

There are no signs of left atrial mechanical activity after sinus rhythm was re-established: one patient with mitral restenosis lacks presystolic murmur; left atrial pressure recording of another patient lacks the ' $a$ ' wave.

Heart muscle biopsy was obtained from 2 patients who underwent mitral valve surgery. Left atrial specimens showed almost complete lack of all muscle structures.

There is thus electrical, mechanical, and histological evidence of left atrial muscle deterioration. It is likely that the electrophysiological factors responsible for initiation and maintenance of atrial fibrillation have disappeared with this deterioration, thereby allowing sinus rhythm to be re-established. 
Abnormal myocardial metabolism in high risk group middle-aged men with type IV hyperlipoproteinaemia

Lennart Kaijser, Brita Eklund, and

Martin Ericsson

The Departments of Clinical Physiology, Karolinska Hospital and Serafimer Hospital and King Gustaf V Research Institute, Stockholm, Sweden

Myocardial extraction of free fatty acids (FFA), glucose, lactate, pyruvate, glycerol, and oxygen was estimated by simultaneous sampling of blood from an artery and the coronary sinus in the fasting state in 10 symptom-free hypertriglyceridaemic (HTG) 42 to 53-year-old men with normal glucose tolerance. Infusions of ${ }^{14} \mathrm{C}$ oleate and ${ }^{3} \mathrm{H}$ palmitate made it possible selectively to estimate uptake, release, and fractional oxidation of fatty acids. Results were compared to a group of normolipidaemic (NTG) men of the same age. At rest palmitate as well as total FFA extraction was higher in HTG than in NTG subjects. Fractional oxidation of oleate did not differ between the groups at rest, but during pacing it increased in the HTG, unlike the NTG subjects, to become significantly higher than at rest. Glucose extraction was lower in HTG than in NTG during pacing though not at rest. Myocardial RQ tended to be lower in HTG than in NTG both at rest and during pacing.

Thus differences in myocardial substrate utilisation between HTG and NTG exist mainly because lipid contribution is higher in HTG.

The Edinburgh-Stockholm study of coronary heart disease risk factors

M. F. Oliver, R. L. Logan, R. A. Riemersma, and W. Lutz

Department of Cardiology, Royal Infirmary, Edinburgh

A. G. Olsson, G. Walldius, S. Rossner, L. Kaijser, and L. A. Carlson

King Gustaf V Research Institute, Karolinska Hospital, Stockholm

The mortality from coronary heart disease (CHD) (ICD 410) in men aged 40 years is 3 times higher in Edinburgh than in Stockholm. A study of CHD risk factors has been undertaken on random samples of 40-year-old men in the two cities (Edinburgh 107 men: Stockholm 82 men). All clinical measurements were conducted under controlled and identical conditions. All laboratory analyses were made in the same laboratories without access to the source of the specimens.

In Edinburgh men serum triglycerides and very low density lipoproteins were significantly higher; high density lipoproteins were lower; and both serum triglyceride and adipose tissue fatty acids were more saturated and lower in linoleic acid. Serum cholesterol and low density lipoprotein concentrations were not significantly different.

The glucose response to a standardised glucose load was the same, but Edinburgh men produced more insulin and produced it earlier than Stockholm men; and free fatty acid and glycerol production was less inhibited.

In Edinburgh, there are more cigarette smokers and they smoke more cigarettes. Systolic and diastolic blood pressures are higher. Alcohol consumption is higher.

Edinburgh men are shorter than Swedish men but there is no difference in weight. They are physically less active and fewer were able to complete a graded bicycle ergometric load.

These metabolic and physical differences go far to explain the difference in CHD incidence between the two cities.

\section{Relation between QT interval and ventricular arrhythmias in acute myocardial infarction}

Mansour Shoaleh-var, Torbjörn Lundman, and Staffan Ahnve

Serafimerlasarettet, Stockholm, Sweden

Out of a total of 947 patients admitted to the CCU at Seraphimer Hospital during a 2-year period all those with acute myocardial infarction and ventricular fibrillation (VF) or ventricular tachycardia (VT, here defined as 10 or more consecutive ventricular ectopic beats with a rate of more than $150 / \mathrm{min}$ ) during the CCU stay were selected. In 7 out of 14 patients with VF and all 33 with VT the QT interval could be measured. The QT interval was also measured in two control groups; one consisted of 40 age-matched patients with acute myocardial infarction without ventricular arrhythmias, the other group of $\mathbf{4 0}$ patients without acute myocardial infarction treated in the CCU. All patients in the group with ventricular arrhythmias showed pathologically prolonged QT intervals and there were statistically significant differences between this group and the control groups in corrected QT mean intervals. If these findings are confirmed, QT measurements ought to be of great 
value in the prediction of malignant ventricular arrhythmias in acute myocardial infarction.

\section{Which drug should be used as an emergency antidote to beta-blocking agents?}

\section{A. Hjalmarsson, F. Waagstein, and R. Ariniego Department of Medicine I, Sahlgrenatan Hospital, Göteborg, Sweden}

There is an increasing use of beta-blocking agents in patients with cardiovascular diseases, including angina pectoris, hypertension, tachyarrhythmias, and myocardial infarction. Because of a more general use, there will be an increasing number of patients with acute heart failure or cardiogenic shock possibly aggravated or induced by the betablockade. The need for an antidote that can completely neutralise the beta-blockade is obvious.

Postinfarction patients in stable condition though previously in failure were haemodynamically investigated using non-invasive techniques. The betablocking agent, metoprolol was given in a dose of $15 \mathrm{mg}$ followed by either isoprenaline or the $\beta_{1}$ stimulating agent $\mathrm{H} 133 / 22$ (Astra) in increasing doses. All effects of the beta-blocking agent were completely neutralised by $\mathrm{H} 133 / 22$, which, however, induced a significant drop in the diastolic and mean blood pressure though there was a distinct increase in heart rate and cardiac output. Three patients with beta-blockade induced cardiogenic shock have been successfully treated with $\mathrm{H} 133 / 22$. It is suggested that $H 133 / 22$ is a useful antidote to beta-blockade.

\section{'Smokers' disease'}

William McKenna, Christopher Chew, and

Celia Oakley

Royal Postgraduate Medical School,

Hammersmith Hospital, London

One hundred and seven consecutive left ventricular and coronary angiograms performed on patients with chest pain who were under 40 years of age were reviewed. The records of these patients were then assessed for previous myocardial infarction and the presence of major coronary risk factors: raised blood fats, hypertension, and heavy smoking plus use of the oral contraceptive pill.

Seventy-one patients had abnormal coronary arteries. Thirty-five had suffered previous myocardial infarction. All 71 patients had one or more risk factors: 54 had raised cholesterol, 49 smoked cigarettes, and 18 had hypertension.
Twenty-four patients who had not suffered previous myocardial infarction had normal left ventricular and coronary angiograms. Twelve had one or more risk factors: 4 had hypertension, 4 smoked, 1 had high cholesterol and 3 smoked cigarettes and had a high cholesterol.

Twelve patients had both clinical and angiographic evidence of previous myocardial infarction but normal coronary arteries. None had abnormal lipids or high blood pressure. Nine were heavy smokers of whom one was taking an oral contraceptive at the time of her myocardial infarction. Necropsy 4 years after myocardial infarction in one of these showed a large myocardial fibrous scar but no coronary atheroma. The 3 non-smokers had none of the recognised risk factors but one gave a history of severe chest trauma and the other of probable coronary spasm.

Smoking was the sole major risk factor in $\mathbf{9}$ of 12 patients with myocardial infarction and normal coronary arteries.

\section{Patients treated in CCU without acute myocardial infarction: high risk subgroup for subsequent myocardial infarction and/or cardiovascular death}

\section{O. Nyquist and R. Nordlander}

Karolinska Institutet, Huddinge Hospital, Huddinge, Sweden

Consecutive patients admitted to the coronary care unit (CCU) of Huddinge Hospital during one year were studied. A diagnosis of acute myocardial infarction could be excluded in 206 of the patients. One hundred and ninety-three of these were retrospectively followed up during a mean of 17 months. The incidence of cardiovascular death was 9 per cent during this period: 41 per cent of the deaths occurred within 3 months and 65 per cent within 6 months. The incidence of acute myocardial infarction, fatal and non-fatal, was 12 per cent; 57 per cent of these occurred within 3 months and 70 per cent within 6 months.

The incidence of transient ST-T changes during the stay in the CCU was 20 per cent. Patients with transient ST-T changes had a 25 per cent incidence of cardiovascular death whereas patients without these electrocardiographic abnormalities had a 4 per cent cardiovascular mortality. The corresponding figures for subsequent acute myocardial infarction, fatal and non-fatal, are 47 per cent and 4 per cent, respectively.

In summary 53 per cent of the patients with transient ST-T changes and 6 per cent without 
these electrocardiographic abnormalities had a coronary event during the follow-up period. These data select a high risk subgroup for subsequent acute myocardial infarction and/or cardiovascular death.

\section{Characteristics of women with angina pectoris}

Results from a longitudinal population study in Göteborg, Sweden

\section{Calle Bengtsson \\ Medicinska kliniken II, Sahlgrenska sjukhuset, Göteborg, Sweden}

A population study of 1462 women was carried out in Göteborg, Sweden, during 1968 to 1969. Women in five age strata between 38 and 60 were studied. Six years later, during 1974 to 1975 , the same population sample was restudied, and 89 per cent of the participants in 1968 to 1969 took part in the 1974 to 1975 study. The women on both occasions were asked about a history of angina pectoris in a standardised way. Altogether 29 women reported symptoms of angina pectoris in 1968 to 1969 . One of these died during the interval between the two investigations. Of those 28 living at the time of the second study, 13 women still reported symptoms of angina pectoris, while 15 women did not. Another 53 women, who did not report symptoms of angina pectoris in 1968 to 1969 , reported such symptoms 1974 to 1975. Characteristics are given of the three groups of women with history of angina pectoris thus obtained: those with symptoms of angina pectoris 1968 to 1969 but not 1974 to 1975 , those with symptoms 1974 to 1975 but not 1968 to 1969 , and those with symptoms on both occasions, and comparison will be made with the population sample as a whole.

\section{Observations on influence of beta-blockade on specificity of treadmill exercise test}

J. Marcomichelakis, R. Donaldson, S. Joseph, B. Kelly, P. Taggart, and Walter Somerville The Department of Cardiology, Middlesex Hospital, London; and Central Medical Establishment, Royal Air Force

In 20 consecutive patients presenting with angina (group 1) a positive ischaemic response to maximum treadmill exercise testing was recorded in 15 . When repeated after an oral dose of $80 \mathrm{mg}$ oxprenolol the test remained positive in all 15 though the degree of
ST segment depression was usually reduced. Coronary arteriography confirmed the presence of important disease (greater than $70 \%$ occlusion of at least one major vessel) in all.

Twenty asymptomatic subjects presenting with an abnormal resting electrocardiogram resembling myocardial ischaemia (group 2) which threatened their professional livelihood, underwent a similar procedure. All had normal coronary arteriograms. A positive exercise test was recorded in $6(30 \%)$ but when repeated after oxprenolol it was negative in all. Specificity was increased from 70 to 100 per cent by the use of beta-blockade.

Caution must be used when extrapolating from the patients in group 1 who presented with angina to people with latent but clinically undetected coronary artery disease. Similarly, patients in group 2 are not representative of a normal population having a higher incidence of false positive tests and probably an altered sensitivity to adrenaline. By the same token they are more likely to improve specificity by the use of beta-blockade than the 'normal person'. The epidemiological terms in this study relate to the anatomy of the coronary arteries and not to clinical eventualities. Greater reliance should be placed on beta-blockade as an adjunct to electrocardiographic diagnosis of coronary heart disease.

\section{Abnormal left ventricular wall movement during isovolumic contraction in patients with coronary artery disease}

\author{
D. G. Gibson, J. H. Doran, T. A. Traill, \\ and D. J. Brown \\ Brompton Hospital, London
}

Left ventriculograms of 90 patients with coronary artery disease were digitised frame by frame and compared with those of 15 normal subjects, in order to investigate events during isovolumic contraction (IVC). In normal subjects, there was an 8 per cent reduction in cavity area before aortic valve opening, because of inward endocardial movement in the upper part of the anterior wall. In 34 patients, segmental abnormalities of IVC were present. These consisted of: type I (14 patients): outward movement of $2 \mathrm{~mm}$ or more during IVC, reaching a maximum 50 to $100 \mathrm{~ms}$ after aortic valve opening, followed by delayed, but otherwise normal, inward movement during ejection; type II ( 9 patients): outward movement during IVC, but reduced amplitude of inward movement during ejection; and type III (11 patients): premature inward endocardial movement in the inferior region. In 12/14 
type I patients, significant abnormalities of isovolumic relaxation were also present in the same regions of ventricle. Type I and II, though involving mainly the apex and inferior wall, were frequently associated with anterior $Q$ waves on the electrocardiogram.

In summary, disturbances of IVC are common in patients with coronary artery disease, and may be associated with impairment of function throughout the cardiac cycle.

\section{Paradoxical motion of ventricular septum in diastole-a unifying hypothesis}

\section{A. J. F. Page and W. A. Littler \\ British Heart Foundation Department of \\ Cardiovascular Medicine, University of \\ Birmingham and East Birmingham Hospital}

One hundred consecutive patients with mitral stenosis, tricuspid regurgitation, atrial septal defect, left atrial myxoma, and prosthetic mitral or aortic valves, alone or in combination with aortic regurtitation or tricuspid stenosis, were examined echocardiographically.

A consistent feature was the posterior movement of the ventricular septum in early diastole, though it occurred somewhat later in cases of atrial septal defect or tricuspid regurgitation.

Differences in the rates of simultaneous left and right ventricular filling provide a unifying hypothesis to explain this abnormality of ventricular septal movement.

\section{Detection of incoordinate left ventricular contraction by $M$-mode echocardiography: comparison with cineangiography}

\author{
T. A. Traill, J. H. Doran, D. J. Brown, and \\ D. G. Gibson \\ Brompton Hospital, London
}

Abnormal left ventricular wall movement during isovolumic contraction and early relaxation was assessed from simultaneous apex and echocardiograms in 50 patients with ischaemic heart disease, and compared with estimates from the corresponding digitised left ventriculograms. During isovolumic contraction, a normal angiogram was accompanied by normal apex-dimension relations in 13 out of 14 cases. In 19 cases, angiographic evidence of discrete outward movement during isovolumic contraction occurred, and was associated with abnormal apex-dimension relations in 15 .
During isovolumic relaxation, of 14 cases normalc. angiographically, apex-dimension relations were $\vec{F}$ normal also in 11, while in 36 patients with abnormal wall movement on angiogram, apex-dimension $\frac{\square}{5}$ relations were abnormal in 30. Correlation was less $\frac{\bar{c}}{\frac{5}{3}}$ good between echocardiographic and angiographic $\vec{\Phi}_{\vec{\sigma}}$ estimates of left ventricular minor dimension $\bigcirc$ $(r=0.75)$, and was absent between those of peak $\omega$ rates of dimension change during systole and $\overrightarrow{0}$ diastole. Asynchronous onset of inward wall move- $\overrightarrow{-}$ ment and the distribution of regional abnormalities ${ }_{\sigma}$ of overall wall movement amplitude were unrelated to apex-dimension relations. Apex-dimension relations are thus a sensitive and specific means of $\stackrel{\vec{D}}{\overrightarrow{0}}$ detecting abnormalities of left ventricular wall movement during isovolumic contraction and early ${ }^{\omega}$ relaxation, unaffected by other manifestations of $ᄋ$ left ventricular disease.

\section{Echocardiographic identification of potential complications after Mustard's operation}

M. L. Rigby and E. D. Silove

Children's Hospital, Birmingham

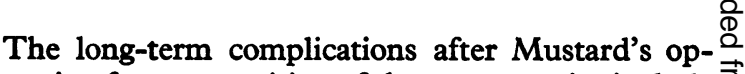
eration for transposition of the great arteries include $\vec{O}$ vena caval and pulmonary venous obstruction by the intra-atrial baffle, atrioventricular valve regurgitation, and subpulmonary stenosis. Since structures involved in these complications can be identified by $\vec{\Phi}$ echocardiography, 30 postoperative asymptomatic patients were studied, 16 with pericardial and $14 \frac{5}{3}$ with 'dacron' baffles.

The baffle was identified in every patient. It was $\stackrel{\circ}{\circ}$ thickened within 2.5 years of operation in 3 of 6 patients with 'dacron' but none of 5 with peri- 을 cardium. Of 19 patients studied more than 3 years $>$ after operation, 13 had developed such thickening irrespective of the baffle material. One of these $N$ subsequently developed vena caval obstruction.

Subpulmonary stenosis in 5 patients was charac- 0 terised by systolic anterior mitral valve movement $\omega$ and early closure, systolic flutter, and late systolic opening of the pulmonary valve. Diastolic flutter $O$ of the atrioventricular valves was usual, possibly $\mathbb{\Phi}$ explaining the occurrence of incompetence. Para- $\stackrel{+}{+}$ doxical septal movement, a small left ventricle, and $\frac{T}{0}$ large right ventricle were common but not as- $\frac{\vec{D}}{\mathrm{D}}$ sociated with right ventricular volume overload.

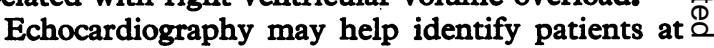
risk of developing vena caval or pulmonary venous obstruction and those with left ventricular outflow $\delta$ stenosis. 
Value of echocardiography in distinguishing valvar from subvalvar aortic stenosis

E. D. Silove, M. L. Rigby, and S. P. Singh

The Children's Hospital, Birmingham

The clinical signs do not always differentiate valvar and subvalvar congenital aortic stenosis and the precise diagnosis may remain doubtful even after left heart catheterisation and angiocardiography. A prospective study was planned to evaluate whether echocardiography might contribute to this differentiation before cardiac catheterisation. Twentynine children ( 4 infants) with clinical aortic stenosis were selected for investigation, the criteria being electrocardiographic evidence of left ventricular strain or the presence of effort syncope or angina, or signs of cardiac failure in the 4 infants.

In 9 of 10 patients with discrete subvalvar aortic stenosis, including one infant in cardiac failure, echocardiography was diagnostic. The aortic valve cusps, after initial systolic opening, showed early systolic closure, coarse flutter, and late systolic opening. The aortic valve excursion was diminished in 8 .

In valvar aortic stenosis only 8 of 19 patients ( 1 of 3 infants) had a convincingly small aortic valve orifice. However, the rapid opening of the aortic valve into a domed position was identified in most of the remaining cases by real-time, two-dimensional echocardiography.

M-mode echocardiography readily identifies patients with clinically severe subvalvar aortic stenosis while real-time, two-dimensional studies are more likely to be diagnostic in those with congenital valvar aortic stenosis.

\section{Echocardiographic and exercise evaluation of results after mitral valvotomy operations}

M. F. Shiu, A. Crowther, B. S. Jenkins, and

M. M. Webb-Peploe

Department of Cardiology, St. Thomas'

Hospital, London

An echocardiographic mitral valve closure index (MVCI) based on the rate of diastolic closure movement of both the anterior and posterior mitral leaflet echoes was found to correlate significantly with the Gorlin mitral valve area in $\mathbf{4 0}$ patients with dominant mitral stenosis (MVCI $=33$ X GMVA -12. $r=0.87 . P<0.01$ ).

Follow-up studies were done in 52 patients 1 to 30 months after mitral valvotomy operations.
Forty-four patients had preoperative echocardiograms and in these, the MVCI showed a significant increase after operation ( $30 \pm 3.9$ to $87 \pm 5 \cdot 1$ (SEM) $P<0.001)$. Five patients with residual grade III (NYHA) symptoms had postoperative MVCI in the severe stenosis range $(37 \pm 13)$. Seventeen patients became asymptomatic, and the mean MVCI in these $(107 \pm 6 \cdot 6)$ was significantly higher than that of the remaining patients with grade II symptoms $(77 \pm 5.8 ; P<0.01)$.

Exercise testing on a bicycle ergometer from 3 months after operation showed significant correlations between the postoperative MVCI and maximum workload ( $P<0.05$ men, $P<0.01$ women), submaximal oxygen uptake $(P<0.01)$, and cardiac index during submaximal exercise $(P<0.05)$, respectively.

It is proposed that the MVCI provides an objective and non-invasive estimation of the severity of mitral stenosis which is of special value when repeated haemodynamic investigations are contraindicated.

\section{Nuclear approach to myocardial infarction}

\section{J. Rowlands \\ Manchester Royal Infirmary}

There is rapidly increasing interest in the use of radioisotopic techniques in the investigation of myocardial infarction. This panel has been organised to enable those interested, but not experienced, in such techniques, to meet, to hear, and to enter discussion with experts on important practical matters in this field.

The promise of isotopic investigation is that it might provide a means of diagnosis, localisation, and sizing of myocardial infarction, that it might distinguish among old scars, recent infarction and ischaemia, that it might assess the effect of these changes on overall circulatory performance, and that it might, through repetitive investigation, provide a means of following these changes with respect to time, both naturally and also after any intervention.

Three main lines of approach have evolved: (i) hot-spot scanning; (ii) ionic tracer scanning; and (iii) dynamic studies. 'Hot-spot' demonstration of freshly infarcted myocardium is now possible using one of several isotopes demonstrably taken up by injured or necrotic myocardium. Ionic tracers are, in the main, chemical or physiological analogues of potassium. They are avidly taken up by healthy myocardium and may be used to delineate the extent of viable, perfused myocardium. 
Dynamic studies are, in the main, undertaken with circulating isotopes. Techniques for estimating total cardiac output, stroke volume, left ventricular ejection fraction, segmental blood volumes (e.g. pulmonary blood volume), and left ventricular wall motion have been devised.

Each technique provides useful information in its own way. Constant effort is being applied to get more detailed information from these techniques. This search for more detail is necessarily limited by technical considerations concerning the physical and chemical properties of the isotopes and the resolving power of the equipment.

This panel sets out to consider the current achievements and limitations of isotopic studies in myocardial infarction.

\section{Ionic tracer scanning in myocardial infarction}

\section{A. Maseri \\ Universita degli Studi di Pisa}

The initial myocardial distribution of ionic potassium analogues appears to follow closely that of regional myocardial perfusion. This behaviour, anticipated on theoretical grounds, was shown by simultaneous measurements with microspheres.

Therefore ischaemic regions initially take up less indicator than well-perfused regions and will appear as cold areas on the myocardial scintigram. However, this initial, flow-dependent distribution is not maintained indefinitely because the final equilibrium distribution of these tracers tends to follow the distribution of the potassium pool and hence basically that of cellular mass. Indeed we have shown that cold areas in initial distribution scintigrams, related to transient transmural myocardial ischaemia, disappear progressively within 1 to 3 hours (transient transmural reduction of myocardial blood flow, demonstrated by thallium201 scintigraphy, as a cause of variant angina (Maseri et al., Circulation (1976), 54, 280-288). Thus while myocardial scintigrams taken 5 to 20 minutes after the intravenous injection of ionic tracers reflect not only the presence of necrosed tissue and of old scar, but also that of the borderzone ischaemic myocardium, scintigrams taken about 3 hours later reflect predominantly necrosis and old scar.

Among the following ionic tracers, ${ }^{43} \mathrm{~K},{ }^{81} \mathrm{Rb}$, $\mathrm{NH}_{3}$, and ${ }^{201} \mathrm{Tl}$, thallium-201 is the nuclide most easily available and suitable for gamma camera studies. The limitations of the technique are the

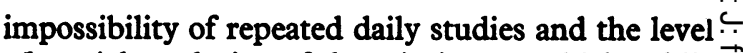
of spatial resolution of the scintigrams which, while $\vec{F}$ : adequate for large size infarcts, may not be sufficient for the detection of small or of subendocardial $\frac{C}{0}$ necrosis. The spatial resolution may be considerably $\frac{\overline{\bar{N}}}{\bar{\alpha}}$ improved by positron emission transaxial tomo- $\mathbb{D}$ graphy in research environments.

\section{Hot-spot scanning}

\section{J. Lessem}

Allmanna Sjukhuset, Malmo, Sweden

Since the late 1960s when Malek reported the possibility of labelling infarcted myocardium with $\frac{\text { S }}{2}$ ${ }^{203} \mathrm{Hg}$-Mercurascan, interest in these techniques $\overrightarrow{-}$ has increased. They became available clinically $\frac{T}{0}$ when it was shown by Bonte and co-workers that $99 \mathrm{~m}$ Tc-pyrophosphate yielded positive infarct scinti- $\overrightarrow{0}$ grams in patients with acute myocardial infarction. 0 Pyrophosphate was believed to have an affinity for hydroxyapatite crystals formed on the mitochondria in necrotic myocardium. It was later shown that several mechanisms, involving macroaggregated molecules as well as residual perfusion, also play an $\stackrel{\mathbb{Q}}{\circ}$ important part in the positive uptake. However, $\overrightarrow{\vec{P}}$ Schelbert proved that pyrophosphate mainly labels $\frac{}{3}$ irreversibly damaged myocardial cells.

With pyrophosphate scintigraphy and a mobile scintillation camera, acute infarcts can be diagnosed within 12 hours of onset. The localisation and size $\mathbb{D}$ of the infarct can be fairly well estimated. The uptake is localised and has high intensity in patients $\frac{5}{3}$ with transmural infarcts. This differentiates it from patients with unstable angina pectoris, where it is $\frac{3}{3}$ less intense and is widespread over the whole myocardial area.

Hot-spot scanning should be used, when acute $\frac{D}{2}$ diagnosis and interpretation of the electrocardiogram and enzyme changes are difficult, for example $N$ in the presence of bundle-branch block, in patients $N$ with permanent artificial pacemakers, and after $\mathrm{\omega}_{\mathrm{\omega}}$ cardiac surgery.

\section{Myocardial infarction: dynamic studies}
A. L. Muir
Royal Infirmary, Edinburgh

Recent developments in the use of radioisotopes? suggest that two techniques measuring left ven- 8 tricular ejection fraction can provide useful in- 
formation in myocardial infarction. The first method is based on the detection of rapid fluctuations in activity as a bolus of tracer material passes through the left ventricle and diastole and systole are identified from the dilution curve. The second method is based on a retriggering technique in which activity detected over the left ventricle from a radioisotope bound to plasma is accumulated over many cardiac cycles and is related to the preceding $\mathbf{R}$ wave. The accumulated activity time curve represents the 'averaged' ventricular volume curve over the entire sampling period. The rate of change of volume in systole is easily computed and in addition end-systole and end-diastole images can be compared to detect any dyskinetic segments.

Many workers have shown results in close agreement with standard cineangiographic techniques. In both the acute and convalescent phase of myocardial infarction these methods can now provide useful information to monitor ventricular response to drug therapy and as a guide to prognosis.

\section{Instrumental and technical capabilities and limitations}

\section{R. A. Shields \\ Manchester Royal Infirmary}

The quality of currently available gamma camera images is discussed in terms of the uniformity of response and spatial resolution of sources at depth in tissue. Estimates are made of theoretical limits to image quality given ideal equipment in practical situations. These figures are interpreted in terms of the size of the smallest detectable lesion in both positive and negative infarct visualisation, and in terms of the accuracy with which the size of a lesion may be measured.

The factors are discussed which relate radioactivity distribution to the regional count rate measured on both standard projections and on computer-derived sectional images, and estimates are given for the accuracy of relative regional uptake measurements.

Wall motion studies are examined; the limits of detectability of motion and the factors affecting time resolution are discussed.

The maximum count rate limitation is explained in relation to dynamic functional studies. Finally estimates are made of the accuracy with which time-activity curves may be derived and of the confidence limits to be expected on calculated parameters such as left ventricular ejection fraction.

\section{Panel E: Pacemaker therapy-present status}

\section{Introduction}

\section{E. Sowton \\ Guy's Hospital, London}

A comparison of indications for pacing, apparatus, and results over the past decade shows all areas of treatment have expanded greatly. Fifteen years ago syncope was almost the only indication, and 10 years ago 75 per cent of pacemakers were implanted for this reason. Today the figure is about 50 per cent. About 1 in 3 pacemakers are implanted for sick sinus syndrome. Pacemakers have been implanted at the age of 1 month, and at 100 years.

Pacemakers using lithium batteries may not provide any cost advantage even allowing for reduced hospital time but are preferred because all failure modes are slow.

Infection and mortality rates have dropped dramatically, and the time in hospital for the first implant has been reduced from an average of 1 month to 6 days. Survival of patients is near that for the normal population though it is worse by a factor of 3 in people with ischaemic heart disease.

\section{Storage and retrieval of pacemaker data}

\author{
A. F. Rickards \\ National Heart Hospital, London
}

The need for reliable information about the performance of pacemakers has prompted many centres to use computers to store relevant information. The requirements of the hospital pacing clinic and the technical department of a pacing service differ somewhat in the sort of data which need to be stored but certain basic information about the patient and generator are common to both. A system in use in London is described and discussed and some results on the longevity of electrode systems and generators are presented.

\section{Indications for different types of pacemaker}

L. Ryden

Sahlgrenska Sjukhuset, Göteborg, Sweden 
Panel $F$

\section{Surgery of valvular heart disease}

M. Braimbridge

St. Thomas' Hospital, London

The surgery of heart disease has changed dramatically over the past decade in terms of the type of patient operated on, the aetiology of the disease, and the risk of surgery. The disappearance of rheumatic fever in the developed countries has abolished valvular heart disease as a major surgical problem in the United States and has reduced it to equal proportions with coronary artery disease in Britain. Only in the Eastern Mediterranean and Asia does the old pattern of cardiac surgery remain.

The aetiology of surgical valve disease in Britain has changed also, with aortic stenosis being due to calcified, congenitally bicuspid valves, aortic regurgitation due to subacute bacterial endocarditis or aortic wall disease, mitral regurgitation to the 'floppy valve' redundant cusp syndrome, and mitral stenosis nowadays a restenosis problem after previous surgery.

The risks of valve surgery have now reached a uniformly acceptable stage in terms of operative mortality and postoperative morbidity and it is now possible to operate on the aortic valve, for instance, with no operative mortality over a 2-year period or more. Operative mortality now depends on the preoperative status of the patients' myocardium and the efficacy of the myocardial preservation technique, with cold cardioplegia becoming the favoured technique in continental Europe and America. The long-term performance of the newer prosthetic and xenograft valves are now the main issue, with no certain data yet available on which the choice of valve can sensibly be made.

\section{Surgery of congenital heart disease}

\section{M. de Leval \\ The Hospital for Sick Children, Great Ormond Street, London}

Over the past ten years, there have been two major changes in the surgical treatment of congenital heart defects: (1) the primary repair of intracardiac defects during infancy and (2) the surgical repair of complex intracardiac defects which were considered inoperable in the past.

Intracardiac repair in infancy is only indicated for patients in congestive heart failure and/or a significant degree of arterial desaturation. There are three major indications: (a) intracardiac anomalies $\stackrel{c}{\Rightarrow}$ for which no palliation is available (i.e., total $\stackrel{\mathcal{P}}{+}$ anomalous pulmonary venous drainage and transposition of the great arteries), (b) anomalies for $\frac{\overline{\bar{c}}}{\text {. }}$ which a palliative operation followed by a cor- $\frac{\bar{D}}{\vec{D}}$ rective operation later, carries a risk at least as high $\stackrel{\mathbb{}}{\circ}$ as a primary repair in infancy (i.e., ventricular septal $\cong$ defects) and (c) congenital heart defects for which $\vec{\circ}$ palliative surgery gives unsatisfactory results, but $\mathrm{a}-$ complete correction seems to be possible (i.e., $\vec{\omega}$ persistent truncus arteriosus and complete atrio- $\frac{\rho}{\partial}$ ventricular canal).

Amongst the complex cardiac defects which are $\vec{\partial}$ now being treated, we should mention persistent $\stackrel{-}{-}$ truncus arteriosus, complex transposition of the $\vec{\omega}$ great arteries, pulmonary atresias with ventricular $\circ$ septal defect, tricuspid atresia and univentricular hearts.

\section{Assessment of myocardial perfusion in angina pectoris using Krypton-81m}

\author{
A. P. Selwyn, A. Kivisaari, G. Forse, K. Fox, \\ T. Evans, D. Fitchett, R. Sapsford, and \\ R. Steiner \\ Cardiovascular Research, Department of \\ Radiology, MRC Cyclotron, Royal Postgraduate \\ Medical School, London
}

Fifteen patients with angina pectoris were studied by left ventriculography and coronary arteriography. After this a specially designed catheter was posi- $-\overrightarrow{0}$ tioned in the aortic sinuses. Krypton-81m (half life 3 . 13 seconds) was continuously infused and quantitative high spatial resolution images of the myocardial distribution of perfusion were recorded at 의 one-minute intervals using a gamma camera. The catheter provided the right and left coronary circu-을. lations individually and simultaneously. The myocardial activity in areas of interest was followed $\%$ using analogue recordings. The images and time ${ }_{0}^{N}$ activity graphs were recorded with each patient at ${ }_{\omega}^{N}$ rest and during atrial pacing. The relation between the coronary stenoses, the appearance of regionalo defects in myocardial perfusion (using ${ }^{81} \mathrm{Kr}^{\mathrm{m}}$ ), chest pain, and the electrocardiogram were noted in? each patient. Thirteen patients showed distur- -0 bances of regional myocardial perfusion during atrial pacing and these were related to stenosed $\stackrel{\odot}{\square}$ coronary arteries and electrocardiographic abnor- $\mathbb{Q}$ malities on exercise. Two patients had normalo coronary arteriograms, normal regional perfusion, and normal electrocardiograms.

Ten patients underwent coronary venous bypass 
graft surgery. The distribution of nutrient blood flow to ventricular myocardium was assessed by a continuous infusion of ${ }^{81} \mathrm{Kr}^{\mathrm{m}}$ into each graft.

These techniques can identify regions of the myocardium jeopardised by functional disturbances of perfusion.

\section{Thallium ${ }^{201}$ exercise scintigraphy in diagnosis of coronary artery disease}

R. G. Murray, J. H. McKillop, A. R. Lorimer, I. Hutton, W. R. Greig, J. G. Turner, and

T. D. V. Lawrie

University Department of Medical Cardiology and Nuclear Medicine, Royal Infirmary, Glasgow

Myocardial imaging after intravenous injection of Thallium $^{201}$ may be useful in the diagnosis of coronary artery disease (CAD). Thallium ${ }^{201}$ scanning (TS) was performed in 39 patients (mean age 46.7 years) presenting with chest pain. Scans were obtained in the anterior, $30^{\circ} \mathrm{LAO}, 60^{\circ} \mathrm{LAO}$, and left lateral projections at rest and immediately after multistage exercise testing. Final diagnosis was established by left ventriculography and selective coronary arteriography.

In 26 patients with $\mathrm{CAD}$, TS perfusion defects were present in 12 at rest and 24 on exercise (sensitivity $92 \%$ ). The electrocardiogram at rest and/or exercise was abnormal in 73 per cent. In 13 patients with normal vessels, perfusion defects were present in 2 at rest and 1 on exercise.

Resting TS perfusion defects were present in 12 patients and corresponded to areas of LV dysfunction in 10 patients. Exercise scanning enhanced the diagnostic accuracy (rest TS sensitivity 46\%; exercise TS sensitivity $92 \%, P<0.005$ ), and perfusion defects on exercise correlated with the distribution of vessel disease on the arteriogram in 20 patients $(77 \%)$.

These results suggest that TS is a useful technique in the diagnosis of myocardial ischaemia. Perfusion defects on resting TS correspond to LV appearance on ventriculography and defects on exercise reflect the presence and distribution of vessel disease.

\section{Segmental quantitative thallium scintigraphy in diagnosis of coronary artery disease-correlation with coronary arteriography and exercise stress testing}

R. J. Wainwright, M. N. Maisey, and E. Sowton Guy's Hospital Cardiac and Nuclear Medicine Departments, London
Myocardial imaging using thallium-201 (Tl-201) was performed in 111 patients with suspected coronary artery disease after intravenous administration of tracer during maximum exercise. The segmental distribution of myocardial T1-201 in 22 patients was quantified and compared with the distribution of tracer in 68 patients with abnormal coronary arteriograms and 21 patients with normal coronary arteriograms who had angina pectoris. Obstructive disease of specific coronary arteries caused corresponding segmental uptake defects so that individual documented disease could be predicted in 98 per cent of LAD stenoses, 83 per cent of LCx stenoses, and 74 per cent of RCA stenoses, with a specificity of 75,68 , and 86 per cent, respectively. Single vessel disease was predicted accurately in 70 per cent of 13 patients and multiple vessel disease in 94 per cent of 53 patients. Exercise electrocardiography was positive in only 55 per cent of the group with obstructive coronary artery disease.

Conversely, abnormal T1-201 uptake defects were detected in $18 / 21(86 \%)$ of patients with angiographically normal coronary arteries and angina pectoris.

Although the sensitivity of detection for obstructive coronary artery disease was 99 per cent the specificity was only 56 per cent with a predictive accuracy of 77 per cent.

Uptake defects seen in stress T1-201 myocardial images cannot be interpreted uncritically as deficits of perfusion or proof of coronary artery disease.

\section{Comparison of rest and exercise thallium 201 imaging with electrocardiography and coronary arteriography}

\section{P. S. Robinson, A. Crowther, D. N. Croft, and D. J. Coltart \\ St. Thomas' Hospital, London}

Before coronary arteriography 51 patients presenting with chest pain were assessed at rest and during maximal exercise by myocardial imaging using Thallium $201\left(\mathrm{Tl}^{201}\right)$ and electrocardiography. Three patients had no coronary artery disease; none had rest $\mathrm{Tl}^{201}$ image defects, and one developed a $\mathrm{Tl}^{201}$ defect on exercise with positive exercise electrocardiographic abnormalities. Fortyeight patients had significant coronary artery disease (CAD) ( $\geqslant 50 \%$ stenosis); 22 had $Q$ waves on resting electrocardiogram, 14 having rest $\mathrm{Tl}^{201}$ defects, 13 in corresponding myocardial segments. $\mathrm{Tl}^{201}$ defects present only on exercise 
were shown in $31(65 \%)$ while diagnostic changes were present on the exercise electrocardiogram in $20(49 \%) \quad(\mathrm{P}<0.05)$. Combined exercise $\mathrm{Tl}^{201}$ imaging and exercise electrocardiogram disclosed diagnostic changes in $37(77 \%)$. This group included 12 with single, 13 with double, and 23 with triple vessel disease. The development of exercise $\mathrm{Tl}^{201}$ image defects was observed in $4(33 \%)$, $9(69 \%)(P<0 \cdot 1)$, and $18(78 \%)(P<0.01)$, respectively.

Considering the 107 myocardial segments supplied by arteries with greater than 50 per cent stenosis, 10 had rest defects only, 33 increased or new defects on exercise, and 64 no defect. Eighteen $(55 \%)$ of those with exercise defects had stenosis of the coronary artery greater than 90 per cent while $16(25 \%)$ of those with no defects had stenosis greater than 90 per cent $(P<0.005)$. Cross filling was shown on coronary arteriography to $14(42 \%)$ of the segments with exercise $\mathrm{Tl}^{201}$ defects and to $11(17 \%)$ of the segments with no $\mathrm{Tl}^{201}$ defects.

In conclusion, exercise $\mathrm{Tl}^{201}$ imaging offers improvement in the diagnosis of CAD in patients with chest pain and can be usefully combined with exercise electrocardiogram. Exercise $\mathrm{Tl}^{201}$ defects are more commonly shown in more severe or more extensive CAD helping selection for arteriography. Cross filling visible at coronary arteriography does not appear to protect against myocardial ischaemia.

\section{Detection of post-infarction left ventricular aneurysms by first pass radionuclide ventriculography, using multicrystal gamma camera}

\section{S. Dymond, P. H. Jarritt, K. E. Britton, and R. A. J. Spurrell \\ Departments of Cardiology and Nuclear \\ Medicine, St. Bartholomew's Hospital, London}

Eighteen patients with a history of anterior myocardial infarction and a suspected diagnosis of left ventricular aneurysm were evaluated by both conventional contrast cineangiography, and radionuclide ventriculography. The isotope study was performed in the right anterior oblique projection, using a Baird-Atomic system 77 multicrystal gamma camera to follow the first pass of an intravenously injected bolus of $10 \mathrm{mCi}$ Technetium $^{99} \mathrm{~m}$ pertechnechate through the central circulation.

Left ventricular ejection fraction was calculated from the high frequency time activity curve generated, a method making no assumptions about ventricular shape. There was a good correlation between the isotope ejection fraction and that calculated from the contrast angiogram by the area-length method $(r=0.86)$.

The radionuclide ventriculogram identified all 14 patients with angiographically demonstrated aneurysms, defined as clearly demarcated akinetic or dyskinetic segments, separate from residual contractile segments, in sinus rhythm; all 4 patients with diffusely hypokinetic ventricles were also successfully identified isotopically.

There was a close correlation between the extent of the akinetic or dyskinetic segment, expressed as a percentage of the total end-diastolic circumference, as assessed by the 2 methods $(r=0.96)$.

First pass isotope ventriculography thus allows non-invasive screening of patients with suspected aneurysms, and provides qualitative and quantitative information on regional and global wall motion abnormalities.

\section{Thallium ${ }^{201}$ scintiscanning, regional myocardial lactate metabolism, and coronary angiography: a correlative study}

M. T. Rothman, G. Jackson, J. Lutkin, Lynne Atkinson, D. E. Jewitt, D. A. Chamberlain, and S. Oram

Departments of Cardiology, Royal Sussex County Hospital, Brighton, and King's College Hospital, London

Angiography can provide accurate localisation of obstructive lesions in the coronary circulation but the sensitivity and specificity of conventional techniques for identifying functional impairment of the myocardium are unsatisfactory. Stress electrocardiograms cannot reliably identify patients with ischaemia or regions of ischaemia. Non-selective lactate measurements reflect overall metabolism of the myocardium but do not accurately localise ischaemic areas. Regional sampling of lactate has theoretical advantages which have not been ade- $N$ quately evaluated. Recently Thallium ${ }^{201}$ scintiscan- N ning has been developed to define regional myocardial perfusion defects. A comparative assessment 0 of scintiscans, regional myocardial lactates, and $\mathbb{\varnothing}$ coronary angiography was undertaken in 15 patients. $\stackrel{\oplus}{\stackrel{\oplus}{+}}$ An excellent correlation was found between thallium $\square$ and lactate methods in patients with abnormal coronary angiograms. The 12 patients with obstructive lesions on angiography were identified $\stackrel{\vec{Q}}{\Omega}$ both by regional lactate and thallium investigations and localisation was reliable. The results in $2<$ patients were normal by all 3 investigations. One응 patient with abnormal lactate and thallium studies 
but normal coronary angiograms was subsequently found to have a fibrotic and hypoplastic right ventricle. Our results indicate that Thallium ${ }^{201}$ scintiscanning and regional lactate studies accurately localise areas of abnormal myocardial metabolism. These tests are safe as out-patient procedures and scintiscans have the added advantage of being non-invasive.

\section{Effect of surgical versus medical treatment on left ventricle in patients with stable angina: a prospective randomised study}

\section{R. Thompson, M. Ahmed, R. Seabra-Gomez, A. Rickards, $M$. Towers, and M. Yacoub Harefield Hospital, Middlesex}

Between May 1974 and February 1976, 66 patients with stable angina were randomly allocated to medical or surgical treatment. The 2 groups were well matched in respect to age, severity of symptoms, risk factors, previous infarction, and extent of coronary disease. Forty-seven (17 medical; 30 surgical) were reinvestigated by repeat left ventricular (LV), coronary, and graft angiography at a mean time of 12 months after randomisation. LV angiograms were analysed by computerised quantitative analysis of segmental wall motion (SWM). Deterioration occurred in 6 patients $(35 \%)$ in the medical group and was related to progressive disease, despite improved collaterals. Six patients $(20 \%)$ showed deterioration after operation which was related to graft occlusion or poor run-off (overall patency rate $92 \%$ ). Perioperative infarction, seen in 5 patients $(13 \%)$, produced deterioration in $S W M$ in only 1 . Improvement in previously abnormal areas occurred in 5 of 9 patients (55\%) after operation. It is concluded that changes in $\mathrm{LV}$ function are closely related to myocardial perfusion and that improvement occurs only in the surgical group.

\section{Left ventricular function before and after coronary bypass surgery}

Per Carlens, Christian Landou, and Kenneth Pehrsson Department of Clinical Physiology, Radiology and Cardiology, Thoracic Clinics, Karolinska Sjukhuset, S-104 01 Stockholm, Sweden

Ten patients with signs of poor left ventricular function (LVF) before coronary bypass operation were restudied haemodynamically and angio- graphically 1 to 2 years postoperatively. A total of 21 grafts were inserted and of these 3 were occluded postoperatively. All patients suffered from intractable angina before operation, while 5 patients (group I) became completely free of symptoms after operation. LVF in these 5 patients returned almost to normal and their coronary arteriograms showed an excellent operative result.

Three patients (group II) were subjectively considerably improved after operation. Of these, 1 patient had good LVF, while the other two had a much improved LVF. On coronary arteriography one patient had one of two grafts occluded, while the other two had new obstructions in non-operated vessels.

Two patients (group III) were subjectively only slightly improved after operation and also had poor LVF. Both patients had one of two grafts occluded and new significant stenoses had occurred.

The study shows that patients with poor LVF before coronary bypass surgery can have nearly normal function postoperatively. Furthermore, there seems to be a good relation between subjective symptoms, LVF, and the result of the operation judged from the coronary arteriogram.

\section{Survival after coronary artery bypass grafting: review of 7 years' experience}

\author{
M. Ahmed, R. Thompson, E. Fawzy, M. Towers, \\ and $M$. Yacoub \\ Harefield Hospital, Harefield, Middlesex
}

Between November 1969 and October 1976, 640 patients underwent coronary artery bypass grafting (CABG) at Harefield Hospital. A total of 1345 grafts or $2 \cdot 1$ grafts per patient were inserted. Additional endarterectomy was performed in 212 patients $(33 \%)$. There were 657 men and 73 women with a mean age of 53.1 years. The indication for operation was angina alone in 395 patients (82 with unstable angina), angina and heart failure in 178, and pure heart failure in 67. Associated procedures included excision of left ventricular aneurysm or scars in 71 patients; aortic valve replacement in 25 patients; mitral valve repair or replacement in 13 patients, closure of ventricular septal defect in 10 and other procedures in 7 patients. There were 33 early deaths $(5.1 \%)$ and 68 late deaths $(10.6 \%)$ in the whole group; with a 5-year actuarial survival of 83 per cent. Of the 395 who were operated on for angina alone, the early mortality was 0.5 per cent and the late mortality 4 per cent. In this group the 5-year actuarial survival was 95 per cent (a yearly mortality of $1 \%$ ). The 
average age of this group was 55.1 years and the number of grafts inserted was $2 \cdot 2$ grafts per patient. In patients undergoing additional excision of $\mathrm{LV}$ aneurysm or scars, the early mortality was $8(11.3 \%)$ and the late mortality $16(22.5 \%)$. Additional aortic valve replacement resulted in early mortality of $1(4 \%)$ and no late mortality; while in patients undergoing additional mitral valve replacement or repair, there were 2 early deaths $(15.4 \%)$ and 5 late deaths $(38.5 \%)$.

It is concluded that the early and late survival after CABG depends on the presence or absence of preoperative heart failure and the need for additional procedures. CABG appears to influence favourably the late survival of patients with angina resulting from multiple vessel disease.

\section{Efiect of coronary grafting on incidence and prognosis of myocardial infarction in patients with stable angina: a prospective randomised study}

\section{Yacoub, R. Thompson, M. Ahmed, and M. Towers \\ Harefield Hospital, Middlesex}

Sixty-six patients with stable angina were randomly allocated to medical or surgical treatment. The 2 groups were well matched with respect to age, severity of symptoms, risk factors, previous infarction, and extent of coronary disease. The presence of diffuse peripheral disease or nonvisualisation of the distal segment at angiography were not regarded as contraindications to operation. One-hundred-and-six grafts were inserted $(2 \cdot 7$ per patient) with additional endarterectomy to 25 vessels $(24 \%)$. There was 1 early death $(2 \cdot 6 \%)$ and 1 late death $(2.6 \%)$ in the surgical group and 4 deaths $(14 \%)$ in the medical group (follow-up 13 to 36 months, mean 22 months). Perioperative infarction (PMI) occurred in 5 patients $(13 \%)$ without mortality and was always in the territory of a patent graft. Late myocardial infarction (MI) was not seen in the surgical group. MI occurred in 6 patients $(21 \%)$ in the medical group with 3 deaths. Computerised quantitative radial analysis of segmental wall motion showed no deterioration in $\mathrm{LV}$ function in 4 of 5 patients following PMI and was associated with normal effort tolerance and absence of symptoms. In contrast deterioration in LV function, symptoms, and effort tolerance occurred in patients in the medical group.

It is concluded that MI appears to be less frequent and carries a better prognosis in the surgical group.

\section{Uptake of noradrenaline by human heart muscle}

M. C. Petch and W. G. Nayler

Cardiothoracic Institute and National Heart

and Chest Hospitals, London

Noradrenaline uptake was studied using heart muscle from 47 patients undergoing cardiac surgery. Slices of right atrium were incubated in KrebsHenseleit solution containing $1.3 \times 10^{-7} \mathrm{M}{ }^{3} \mathrm{H}-$ noradrenaline; after 10 minutes incubation the tissue:medium ratio for a group of patients with coronary heart disease and normal resting cardiac function was $9 \cdot 28 \pm 2 \cdot 84$. In patients with cardiac failure uptake was significantly lower, the concentration ratio being $5.46 \pm 1.53(P<0.001)$; in a similar group of patients the ratio for left ventricular muscle slices was only $2.98 \pm 0.91$.

Uptake was inhibited not only by increasing the noradrenaline concentration in the incubation medium, but also by adding the drugs desmethylimipramine, amitriptyline and ouabain. Adrenaline was taken up whereas isoprenaline was not. These are the characteristics of the neuronal uptake process which has not been shown before in human myocardium.

It is suggested that the neuronal uptake of the sympathetic neurotransmitter noradrenaline, and of circulating catecholamines, plays an important role in the regulation of cardiac activity in man, as it does in experimental animals.

\section{Factors influencing development of hypoxic contracture}

M. J. Lewis, A. C. Grey, and A. H. Henderson Departments of Pharmacology and Cardiology, Welsh National School of Medicine, Cardiff

Diastolic or resting tension can increase at constant length ('contracture') during experimental hypoxia or ischaemia. This phenomenon is seen in 'stone heart' and possibly during clinical ischaemia. Its mechanism is controversial. Earlier studies indicated that it was energy-dependent but more recent findings (e.g. with verapamil) have led to suggestions that it may be related directly to resting myoplasmic calcium level. We have further studied the effect of various interventions on hypoxic contracture of isolated cardiac muscle preparations. Contracture appears to be altered by manipulation of energy availability $\left(\mathrm{Po}_{y}\right.$, glucose, or free fatty acid) but not by potentially inotropic interventions (low $\mathrm{Ca}$, verapamil, dl-propranolol) when any secondary 
effect of these on energy utilisation is avoided by using non-contracting muscles. Acidosis and lowered temperature reduce contracture in resting as in contracting muscles, indicating that their effect is not due solely to an energy-sparing negative inotropic action. Species differences in susceptibility to hypoxic contracture were also shown. The findings imply that hypoxic contracture is related primarily to energy availability. Hypoxic contracture is to be distinguished from contracture induced by reoxygenation, which is not normally seen in these preparations but can be elicited under conditions associated with increased intracellular to extracellular sodium gradient.

\section{Myoglobin and creatine kinase in serum in patients treated in a coronary care unit}

Christes Sylvén

Med. Clin. III, St. Erik's Hospital, 11282 Stockholm, Sweden

Serum creatine kinase (CK) myoglobin (MG) were determined in 49 consecutive patients referred to a coronary care unit: their symptoms had lasted less than 6 hours. Of 18 patients, $15(83 \%)$ with acute myocardial infarction (AMI) had increased concentrations of $M G$ at admission while $5(28 \%)$ had increased CK values. Peak levels were found after 9.4 (MG) and 23.0 hours (CK) after onset of symptoms. The relative increases of $M G$ and $C K$ were similar. Of 31 patients diagnosed as nonproven AMI, 11 had MG and/or CK elevations. In these 11 patients $M G$ and $C K$ peaks were timerelated to each other as in the AMI group, but both appeared significantly earlier, at 4.3 (MG) and 10.0 hours (CK). Eight had MG peaks above the upper reference limit and of them three were above the lowest level found in patients with AMI. Transient electrocardiographic abnormalities were three times more common in this group than in the remaining 20 patients.

In conclusion the study shows MG to be an early and sensitive indicator of AMI. Any potential value of $M G$ in subgrouping non-proven AMI remains to be settled.

\section{Prolonged protective effect of propranolol on hypoxic heart muscle}

W. G. Nayler, C. E. Yepez, and R. Ferrari Cardiothoracic Institute, University of London, 2 Beaumont Street, London

The acute administration of in vitro racemate propranolol protects adult heart muscle against some of the deleterious consequences of hypoxiaestimated by reduced enzyme leakage, a slowed rate of rise of resting tension and the preservation of mitochondrial function. We have investigated whether this protection occurs after the in vivo administration of the drug, and have determined how long it persists after cessation of therapy.

Adult rabbits were given $2.0 \mathrm{mg} / \mathrm{kg}$ propranolol subcutaneously, twice daily for 5 to 6 days. The hearts were isolated, paced, and perfused with aerobic or hypoxic buffer. Coronary effluent was collected for CK analysis. Resting tension was monitored and the mitochondria were isolated and assayed for respiratory and $\mathrm{Ca}^{2+}$-accumulating activity.

Hearts removed one hour after the last dose of propranolol had been given released less CK and had a slowed rate of rise of resting tension during hypoxic perfusion, relative to the controls. Mitochondrial RCI, $\mathrm{QO}_{2}$, and $\mathrm{Ca}^{2+}$-accumulating activity was maintained at control levels despite the hypoxic perfusion. The protective effect of propranolol was still evident 72 hours after the last dose had been given, at a time when no $\beta$-blockade was evident.

\section{Surgical correction of complete atrioventricular canal in infants and children}

Christopher Lincoln, Roxane McKay, Graham Miller, Michael Joseph, and Elliot Shinebourne

Department of Cardiac Surgery and Paediatric Cardiology, Brompton Hospital, London

The surgical correction of complete atrioventricular canal has been performed in 16 young children under the age of 7 years. Seven were under 1 year, and none had been previously palliated.

The average age and weight were 30 months and $9.7 \mathrm{~kg}$, respectively. Eleven were below the third centile for height and weight. Eight were in chronic congestive cardiac failure. Down's syndrome was present in 4.

Cardiac catheterisation showed that the $Q P / Q S$ ranged from 1.1 to $4.9 \overline{2 \cdot 7}, \mathrm{RVP} / \mathrm{LVP}$ ranged from 0.6 to $1.2 \overline{0.8}$, and pulmonary arteriolar resistance (PAR) from 0.6 to 14 4.7.

In 12 , the anterior common leaflet was tethered by chordae to the crest of the interventricular septum, and in 4 this leaflet was floating free. Latterly, a two-patch technique has been used to replace the deficiency in the atrioventricular septa, 
appearing to be a more secure method than previously described techniques. There were 6 hospital deaths. Three resulted from avoidable or technical reasons. In one the pulmonary arteriolar resistance was $14.7 \times \mathrm{m}^{2}$. In one there were other complex malformations of the heart, and in another a fatal cerebral abscess occurred.

Ten patients were discharged from hospital, and in 7 elective recatheterisation was performed. The $\mathrm{QP} / \mathrm{QS}$ ranged from 1.0 to $1.6 \overline{1.2}, \mathrm{RVP} / \mathrm{LVP}$ ranged from 0.2 to $0.9 \overline{0.5}$, and PAR 0.8 to $5 \cdot 3 \overline{2 \cdot 2}$. All the survivors are clinically improved.

\section{Correction of ostium primum defect- late complications}

\section{G. R. Sutherland and Jane Somerville \\ Paediatric and Adolescent Unit, National Heart Hospital, London}

Fifty-eight patients aged 2 to 33 years left hospital after closure of an ostium primum defect with repair of the mitral valve. All have had full clinical evaluation 2 to 16 years later. Fifty were followed more than 5 years and 29 were recatheterised.

There have been 3 late deaths, one occurring at reoperation for mitral regurgitation, another after infective endocarditis during pregnancy, and one 9 years later in a patient with persistent complete heart block.

Four patients have had reoperation for mitral regurgitation which had progressed slowly in 3 and become severe during pregnancy in the fourth. A further $\mathbf{4 4}$ have mild to moderate mitral regurgitation. Three patients have a small residual atrial septal defect.

Other complications developed in 10 patients: infective endocarditis in 2, recurrent paroxysmal arrhythmias in 3, and progressive conducting tissue abnormalities in 5. Electrophysiological studies have shown lesions in AV nodal and distal conducting tissue.

At present 49 patients are well without cardiac symptoms. Only 5 patients have none of the above complications.

We conclude that patients who had surgical repair of an ostium primum defect require longterm medical supervision in view of the high incidence of residual abnormalities.

\section{Results of surgical correction of complete atrioventricular canal}

D. K. C. Cooper, M. de Leval, and J. Stark The Hospital for Sick Children, Great Ormond Street, London
During 1957 to 1974, 28 infants with complete atrioventricular canal (CAVC) and intractable heart failure underwent pulmonary artery banding (PAB); 8 died (28\%). Complete repair of CAVC was carried out in 21 children aged 2 months to 14 years (average age 4.0 years) between 1971 and 1977. Nine had undergone previous PAB. The operative technique of Rastelli and his colleagues was followed, with one minor modification: the suture line was carried from the right side of the interventricular septum around the coronary inus, which was left to drain into the left atrium, thus avoiding the region of the atrioventricular node. His bundle mapping was not used. Seven of 21 operated children died (33\%), significant mitral valve ring hypoplasia and leaflet deformity being a contributory factor in 3 patients. Atrioventricular dissociation occurred in one patient who died. The mortality rate was 20 per cent in uncomplicated CAVC, and was not significantly increased by previous PAB. Among 5 infants there was 1 death (an infant aged 2 months). There have been no late deaths. The overall survival rate has improved. During 1971 to 1974,8 were operated with 5 deaths $(63 \%)$, but since 1975 , only 2 out of 13 have died $(15 \%)$.

\section{Management of persistent truncus arteriosus in infancy}

J. Stark, M. de Leval, D. Gandhi, F. Macartney, and J. Taylor

The Hospital for Sick Children, Great Ormond

Street, London

During 1957 to 1974, infants with persistent truncus arteriosus (PTA) in intractable heart failure (IHF) were treated by pulmonary artery banding (PAB). The operative mortality was 66 per cent. There was one late death. Since 1974 the policy of early 'total repair' was followed in 13 infants with PTA. They are discussed in 3 groups. (a) 4 infants dying before surgery, ages $2,4,8$, and 8 days; 2 also had interrupted aortic arch, and all were in severe heart failure and metabolic acidosis. (b) 8 infants operated urgently for IHF; 4 , aged 28 days, 2,5 , and 6 months, survived the operation and are well up to 34 months; 4 infants, aged 5 and 8 days, 5 and 9 months died: 2 deteriorated during cardiac catheterisation with $\mathrm{pH}$ below 7.0, and 2 died on the table, 1 from a technical error. (c) One infant was offered operation despite a pulmonary vascular resistance raised to levels considered inoperable by the normal criteria, because he was only 11 months old. He died and histology showed grade III 
pulmonary vascular obstructive disease. Data presented confirm that early total correction is feasible even in neonates and that an aggressive approach to early diagnosis and treatment is required.

\section{Late clinical and haemodynamic results in patients after Fontan procedure}

\section{R. Radley-Smith and M. Yacoub Harefield Hospital, Middlesex}

Eight patients aged between 12 months and 34 years who underwent successful Fontan procedure, for tricuspid atresia or single ventricle, have been followed up for between 3 and 42 months (mean 20.6). Fresh, adult sized, antibiotic sterilised aortic homografts were used for the conduit in 7 and the patient's own pulmonary valve in 1 . Five patients had additional homografts inserted as atrial inflow valves and 3 patients had none. Two patients without additional valves died 12 months after operation in progressive right atrial failure with oedema and hepatomegaly. The remaining child, without additional valves, also had signs of right atrial failure at 30 months. The 5 patients with additional valves are well with no evidence of failure. Late reinvestigation, at least 12 months after operation, in 6 patients showed no significant gradient across the pulmonary valve and small gradients across the atrial inflow valves. In those patients with additional valves the 'diastolic' pressure in the atrial trace was low (between 2 and $6 \mathrm{mmHg}$ ), whereas this pressure was equal to the pulmonary artery diastolic pressure in those patients without additional valves. Pulsatile flow through the pulmonary arteries was shown in all patients.

It is concluded that patients undergoing the Fontan procedure appear to have better clinical and haemodynamic results if they have additional inflow valves.

\section{Intraoperative identification of intraventricular specialised conduction tissue in univentricular heart}

\section{G. I. Fiddler, J. D. Maloney, G. K. Danielson, D. C. McGoon, and D. G. Ritter Mayo Clinic and Mayo Foundation, Rochester, Minnesota, USA}

Intraoperative identification of the intraventricular course of specialised conduction tissue (IISCT) is a recently evolved technique which, by allowing adjustments during surgical repair procedures, may lessen the likelihood of injuring the conduction tissue with the subsequent development of heart block.

IISCT has been performed in 35 patients with a univentricular heart undergoing septation of the ventricular chamber. Thirty patients had an outflow chamber (type A Van Praagh) and 5 had no outflow chamber (type C Van Praagh). IISCT was successful in all the patients except 4 with type $A$ anomalies. In type $A$ hearts the tissue was identified anteriorly along the rim of the bulboventricular foramen and on to the anterior ventricular wall. In type $\mathbf{C}$ hearts the tissue was identified in a muscular ridge present on the posterior wall of the ventricle.

Of 27 patients previously in sinus rhythm and in whom IISCT was successful, 21 maintained sinus rhythm whereas all the patients in whom IISCT was unsuccessful developed heart block.

IISCT can be successfully performed in the majority of patients with a univentricular heart and is a useful technique in the surgical management of these patients.

\section{Regular ventricular rhythm in spite of atrial fibrillation \\ Study with oral Verapamil in high doses}

S. Bertil Olsson, Amrit Khalsa, and

Nils Edvardsson

Department of Cardiology, Med Clin I, Sahlgren Hospital, Göteborg, Sweden

Intravenous verapamil can induce a distinctly regular ventricular rhythm during atrial fibrillation (AF). We have, therefore, studied how high oral doses of verapamil may influence ventricular regularity in patients with AF.

Eighty $\mathrm{mg}$ verapamil resulted in ventricular regularity in 1 patient out of 10 . In 10 other patients, ventricular regularity was obtained after a dose of $240 \mathrm{mg}$ verapamil in $6,320 \mathrm{mg}$ in 2 , and $400 \mathrm{mg}$ in the remaining 2 patients. The mean heart rate decreased from 87 to 58 beats $/ \mathrm{min}$ after $240 \mathrm{mg}$ verapamil by mouth. Side effects limited a chronic oral treatment to 1 out of 10 patients.

Isoprenaline and atropine raised the heart rate and in general did not affect the ventricular regularity. Moderate physical exercise raised the heart rate to about the same extent as was seen during a later achieved sinus rhythm. Ventricular regularity vanished in 7 out of 9 patients during physical exercise.

All patients who originally complained about the 
sensation of cardiac irregularity during AF expressed a feeling of well-being or relief when regular ventricular rhythm was induced by verapamil.

The study indicates that selected patients with $\mathrm{AF}$, who cannot be converted to sinus rhythm or maintain sinus rhythm, may benefit from high doses of verapamil.

\section{Morphological changes in myocardium induced by prolonged beta-adrenoceptor blockade}

E. M. Vaughan Williams, J. Tasgal, and A. E. G. Raine

Department of Pharmacology, University of Oxford

Previous work showed that 6 weeks of betablockade at clinical dose levels produced secondary effects in young rabbits, which persisted after elimination of all drug from the body. (1) Action potential duration was lengthened in atria and ventricles. (2) Myocardial dry weight fell in relation to body weight, but muscle water increased. There was no residual beta-blockade or negative inotropic action. Computer-assisted point-counting of individual organelles in electron micrographs from similarly treated animals has revealed a relative reduction in the total intracellular volume occupied by mitochondria, and a corresponding increase of sarcoplasm. The volumes of the myofibrils and nuclei were not altered. The volume occupied by vascular elements increased, but the interfibrillar distance decreased, offering a shorter pathway for diffusion of oxygen. The latter might explain the beneficial effect of beta-blockade in angina pectoris. The reduced dry weight of the heart may be relevant to the treatment of HOCM in infants, because there is evidence that prolonged treatment with beta-blockers causes a reduction of gradients which persists after cessation of treatment. Thus the hypertrophy itself may be reduced.

\section{Human pharmacological studies with H 80/62, a selective beta $a_{1}$ adrenoreceptor agonist}

Ola Rönn, Gillis Johnson, Lars Jordö, Per Lundborg, and John Wikstrand Department of Medicine II and Department of Clinical Physiology, Sahlgrenska sjukhuset, Göteborg and AB Hässle, Mölndal, Sweden

In animal studies $\mathrm{H} 80 / 62$, and its laevoisomer
H $133 / 22$, has been found to be a beta-adrenoreceptor agonist with high selectivity for beta ${ }_{1}$ receptors.

The aim of the present study has been to see if the haemodynamic effects on animals could also be found in man, to study tolerance to the drug, and to study the interaction between $\mathrm{H} \mathrm{133/22}$ and the beta 1 selective adrenoreceptor blocker metoprolol. The studies have been performed on healthy volunteers.

$\mathrm{H} 80 / 62$ given intravenously in a dose of $20 \mu \mathrm{g} / \mathrm{kg}$ or orally 20 to $40 \mathrm{mg}$ decreased the total electromechanical systole, the pre-ejection period (PEP), and the left ventricular ejection time (LVET). The systolic blood pressure increased about $15 \mathrm{mmHg}$ whereas the diastolic blood pressure and the heart rate remained unchanged.

In a tolerability study $80 \mathrm{mg}$ of $\mathrm{H} 80 / 62$ was given in a sustained release preparation divided in four doses over a period of 36 hours. The substance was well tolerated.

In an interaction study with metoprolol given in three doses over 20 hours in a total dose of $150 \mathrm{mg}$ it was necessary to increase the dose of $\mathrm{H} 133 / 2212$ times to be able to achieve the same effects on systolic blood pressure and systolic time intervals compared with the dose before the beta-blockade. These results indicate that the drug may reverse unwanted haemodynamic effects of beta-blockers.

\section{Oral hydrallazine in management of congestive cardiomyopathy}

\section{H. Fitchett, J. A. Marin Neto, C. M. Oakley, and J. F. Goodwin Division of Cardiovascular Disease (Clinical Cardiology), Royal Postgraduate Medical School, Hammersmith Hospital}

We have studied the effects of hydrallazine in 10 patients with angiographically proven and clinically stable congestive cardiomyopathy, while they were on an otherwise unchanged regimen of treatment and activity.

In 8 patients intravenous hydrallazine resulted in a 87 per cent rise in stroke volume, a 34 per cent fall in left ventricular filling pressure (pulmonary artery diastolic pressure PADP) and a small constant fall $(-5 \%)$ in heart rate. Two patients with gross left ventricular dilatation yet normal filling pressures, though having similar increases in stroke volume, had pronounced rises in heart rate and no change in PADP.

After 4 to 6 weeks of oral hydrallazine 200 to $300 \mathrm{mg}$ daily in 7 patients symptomatic benefit 
was evident in 5 . Restudy in 6 showed a 71 per cent rise in stroke volume, a 28 per cent fall in PADP, and no significant change in heart rate. Forty-eight to 72 hours after oral hydrallazine withdrawal the measured haemodynamic parameters had returned to values close to those recorded before treatment (PADP $-6 \%$, heart rate $+2 \%$ ) but stroke volume was still slightly raised $(+24 \%)$.

The haemodynamic benefit from hydrallazine after 4 to 6 weeks of oral treatment was thus similar to that induced by the acute intravenous injection and was largely lost after stopping the drug for 48 to 72 hours. It was concluded that long-term oral hydrallazine may be a useful adjunct to the treatment of patients with heart failure resulting from congestive cardiomyopathy.

\section{Pacing for optimal function in spectrum of sick sinus syndrome and atrioventricular block}

\section{R. Sutton \\ Westminster Hospital, London}

With the advent of reliable endocardial sensing and stimulation in the right atrium and advances in pacemaker technology, it is now possible to review patients presenting for pacing seeking the most physiologically appropriate stimulation mode. The most recent consecutive 27 patients at this clinic have been studied. Eight $(30 \%)$ were syncopal because of sick sinus syndrome which was documented by electrocardiography and/or Holter monitoring. By electrophysiological and haemodynamic investigation including His bundle electrograms, right heart and arterial pressures and cardiac outputs, 3 were shown to have optimal function with atrial pacing and have no HisPurkinje disease. Four showed no benefit of atrial pacing over ventricular and 1 had poor haemodynamic function on ventricular pacing compared with atrial stimulation but also trifascicular block; function was restored by atrioventricular sequential pacing. Of the remaining $19(70 \%)$ patients who were in stable or intermittent complete heart block, 17 showed evidence of additional abnormal sinoatrial node function. Seven $(37 \%)$ were in atrial fibrillation and $10(53 \%)$ showed sinoatrial block on electrocardiography and/or much prolonged sinus node recovery times. These 17 patients were paced ventricularly. However, in the future some of this type of patient will be considered for either atrioventricular sequential or universal pacing. The 2 $(10 \%)$ patients who showed normal sinoatrial node function received atrial synchronous ventricular inhibited pacemakers. This preliminary series provides a basis for application of new pacing systems.

\section{Central and peripheral haemodynamics in patients with deleterious effects of artificial cardiac pacing}

\author{
O. Edhag, B. Fagrell, U. Freyschuss, \\ L. Kaijser, and H. Vallin \\ Serafimerlasarettet, Stockholm, Sweden
}

Most patients artificially paced because of intracardiac conduction disturbances gain benefit from the treatment. However, some do not improveeven deteriorate- because of interference or loss of atrial transport. Such effects can be shown by invasive haemodynamic studies.

The present study has been designed to evaluate the possibility of using a simple non-invasive technique, digital strain-gauge plethysmography, for the same purpose.

In 6 patients with clinical signs of deterioration when on permanent ventricular pacing, simultaneous recordings of (1) digital pulse volume, and (2) central haemodynamics (CO, aortic and PA pressures) during ventricular pacing (VP) and optimally synchronised atrial-ventricular pacing (AV-P) were made.

In this group of patients a significant increase in CO was recorded with AV-P compared to VP $(1.2 \pm 0.71 / \mathrm{min} ; \mathrm{P}<0.01)$.

Within each pacing mode, in the different patients, beat-to-beat analysis showed a remarkable correlation between digital pulse volume and aortic pulse pressure ( $r: 0.77$ to 0.99 ).

Thus, a great beat-to-beat variation in the peripheral pulse volume implies a great variation in central haemodynamics. This non-invasive technique can be used as a screening method to reveal a negative influence of asynchronous atrial activity in ventricular paced patients who have not had benefit from this treatment.

\section{Low amplitude electrical activity preceding right atrial electrogram in man}

\section{A. Mackintosh, R. Jenner, R. Vincent, D. Woollons, and D. Chamberlain University of Sussex, Brighton}

No reliable technique has been described for recording the activity of the intact human sinus node. 
On theoretical grounds a very low amplitude and low frequency signal would be expected before the first deflection of the conventional atrial electrogram. Intracardiac electrodes were positioned at the superior vena cava/right atrial junction to record very small signals in the high right atrium. They were recorded on electromagnetic tape after filtering and considerable amplification. Subsequent signal averaging by a digital computer greatly reduced random background noise and permitted further amplification. Fourteen subjects showed recognisable electrical activity of about 100 nanovolts which was present 50 to $165 \mathrm{~ms}$ before the conventionally recorded high right atrial electrogram. In some subjects the early signal seemed to continue into the atrial electrogram, while in other subjects it was transient. This preatrial deflection may represent activity in the region of the sinus node. Three of the 14 subjects had electrocardiographic or ambulatory monitoring evidence of sinus node disease, $8 \mathrm{had}$ evidence of other forms of conducting system disease, and 3 were healthy volunteers. No systematic difference has yet been found in the preatrial deflection between these groups.

\section{Antibodies to Coxsackie $B$ viruses in primary congestive cardiomyopathy}

C. G. C. MacArthur, G. Cambridge, A. P. Waterson, J. F. Goodwin, and C. M. Oakley Departments of Medicine and Virology, Royal Postgraduate Medical School, London

The causal relation of Coxsackie B group viruses to myocarditis is now well established. Several cases of prolonged cardiac enlargement or dysfunction after acute myocarditis have been reported. Coxsackie B virus neutralisation titres remain raised for several months after acute infection, which is often subclinical. We have investigated them in 50 patients with primary congestive cardiomyopathy, confirmed by haemodynamic study (48 cases) or at necropsy ( 2 cases). Other cardiac patients admitted for catheterisation during the same period were also studied. The nearest age and sex matched control was selected from this group for each cardiomyopathy patient after exclusion of those with infective or inflammatory disease.

Fifteen patients with cardiomyopathy had titres to a Coxsackie B virus $\geqslant 1024$ compared to only one control. Titres $\geqslant 512$ were more common in the patients. The frequency of high titres was greater in the cardiomyopathy patients who gave a history of cardiac symptoms for $\leqslant 1$ year before study. Among the controls titres in those with and without cardiac failure were similar. HLA-antigens were also analysed in 20 cardiomyopathy patients and did not differ from the general population. These findings provide additional supportive evidence of Coxsackie B virus involvement in primary congestive cardiomyopathy but do not support the suggested role of specific HLA-antigens as conditioning factors.

\section{Enzyme activities in endomyocardial biopsy samples from patients with cardiomyopathy}

P. J. Richardson, Lynne Atkinson, and S. Oram Cardiac Department, King's College Hospital, London

Endomyocardial biopsy was performed in 27 patients with clinically and angiographically proven cardiomyopathy. Samples were examined histopathologically and enzyme activities were assayed and expressed as $\mathrm{mU} / \mathrm{mg}$ protein.

In primary congestive cardiomyopathy (COCM) enzyme activities were significantly lower than those in alcohol-induced cardiomyopathy: creatinine kinase (CK) $(P<0.05)$, lactate dehydrogenase $(\mathrm{LDH})(\mathrm{P}<0.01)$, malic dehydrogenase $(\mathrm{MDH})$ $(P<0.002), \alpha$-hydroxybutyric dehydrogenase $(\alpha H B D)(P<0.005)$. Similarly, patients treated with cytotoxic therapy had significantly higher enzyme activities as compared with those patients with primary COCM: CK $(P<0.02)$, LDH $(P<0.01)$, MDH $(P<0.005)$, aHBD $(P<0.005)$. Enzyme activities of muscle from patients with cardiomyopathy induced by either alcohol or cytotoxic therapy were not significantly different. In histologically proven myocarditis higher activities of all enzymes were found when compared with primary COCM, but these changes were not statistically significant.

In hypertrophic cardiomyopathy (HOCM), myocardial enzyme activities were significantly greater than in all patients with COCM. The significance of these changes was further increased when the HOCM and primary COCM groups were compared: CK ( $P<0.005)$, LDH $(P<0.001), M D H$ $(P<0.005)$, $\alpha \mathrm{HBD}(P<0.002)$.

Myocardial enzyme estimations show not only significant differences between HOCM and COCM, but also enable separation of those patients with primary COCM from those with altered myocardial function induced by alcohol. 
Right ventricular hypertrophy: clinical and ultrastructural relations

\author{
M. Jones and V. J. Ferrans \\ National Heart, Lung and Blood Institute, \\ Bethesda, Maryland; and Johns Hopkins \\ Hospital, Baltimore, Maryland, USA
}

The myocardium of 75 patients with right ventricular pressure overload was studied by light and electron microscopy. The patients were divided into 4 groups: I (36 patients) aged 10 months to 10 years, II (22 patients) aged 11 to 20 years, III (8 patients) aged 21 to 29 years, and IV ( 9 patients) aged 30 to 53 years. Half of group III and 78 per cent of group IV patients suffered cardiac failure, major arrhythmias, operative mortality, or late deaths. Alterations of cardiac hypertrophy were severe in those patients. Prominent interstitial fibrosis was observed in groups I, II, III, and IV at frequencies of $19,23,25$, and 100 per cent, respectively. Myofibrillar lysis, myelin figures, smooth endoplasmic reticulum proliferation, and cell membrane associated spherical microparticles were less common in groups I, II, and III (0 to $25 \%$ ) than in group IV (67 to $100 \%$ ). Cellular atrophy, disorganisation of cells and myofibrils, lipid accumulation, intracytoplasmic junctions, and thickened basal laminae were frequent in cardiac muscle from groups III and IV. The degenerative morphological alterations of chronic right ventricular hypertrophy in man are related to clinical myocardial dysfunction. These relations have implications for long-term prognosis, timing of operations, and surgical requirements for myocardial protection.

\section{Interventricular septal motion in hypertrophic cardiomyopathy (HCM)}

\section{J. Gehrke}

Department of Medicine, Division of Cardiovascular Disease (Clinical Cardiology), Royal Postgraduate Medical School, Hammersmith Hospital, London

The interventricular septum, as visualised by $\mathrm{M}$-scan echocardiography, has been described as immobile and accepted as a characteristic diagnostic feature. Real-time B-scan echocardiography in 20 patients with HCM has shown that the basal septal bulge exhibits a forceful contraction towards the cardiac apex, and the more apical part contracts normally towards the left ventricular posterior wall. The movement of the septal bulge is perpendicular to the direction of the single ultrasonic beam, and can, therefore, not be appreciated in its true amplitude of motion. Depending on beam direction in $M$-scanning an apparently immobile septum may be obtained when imaging the base, and a normal or often hyperkinetic one when pointing towards the apex.

In conclusion, real time B-scan echocardiography has revealed that the entire interventricular septum in HCM is very contractile. The change in upper septal bulge contraction may have an underlying physiological mechanism to prevent additional narrowing of the LV outflow tract (LVOT) during systole, but still enable the upper septal portion to contribute to $\mathrm{LV}$ ejection. This may also enhance the development of an LVOT gradient between the areas on either side of the upper septal bulge. The malalignment of myocardial fibres within the septal bulge, seen as a relative damping of echoes adjacent to its bright LV endocardial border, may be the histological manifestation of this mechanism. The presence of a mobile and thickened interventricular septum, judged from only a limited area of the heart on M-scanning, should not exclude the possible diagnosis of HCM, unless mobility of the entire septum has been shown on a continuous sweep. The diagnosis of HCM, however, is more easily made by real time B-scan echocardiography.

\section{Congenital heart block and maternal connective tissue disease}

E. Esscher and J. S. Scott

Akademiska Sjukhuset, Uppsala, Sweden; Leeds Maternity Hospital

Until recently only few isolated cases of maternal systemic lupus erythematosis and congenital heart block have been reported. From data available in a co-operative European study on congenital heart block and from personal communications we have found 12 mothers with SLE or other closely related disease. Out of their 19 children 11 had isolated congenital heart block and one child had a persistent ductus as well. Two out of these 12 have died.

In a preliminary study laboratory signs of connective tissue disease were searched for in 13 symptom-free Swedish mothers. They had 17 children with isolated congenital AV block III and one with corrected transposition and AV block II. Seven of the 13 mothers with 8 living and 2 dead 
children had laboratory signs of connective tissue disease: raised IgG and/or positive ANF and/or pathological $\mathrm{C}_{3}, \mathrm{C}_{4}$. Six mothers with 5 living and 3 dead children had no signs of disease.

This study supports the finding that connective tissue disease is one important aetiological factor in congenital heart block as proposed by McCue et al. (1977) and Chameides et al. (1977).

\section{References}

Chameides, L., Truex, R., Vetter, V., Rashkind, W., Gatiato, F. M., and Noonan, J. (1977). The association of maternal systemic lupus erythematosus with congenital complete heart block. Circulation, 53-54, Suppl. II, 228.

McCue, C., Mantakas, M., Tingelstad, J., and Ruddy, S. (1977). Congenital heart block in newborns of mothers with connective tissue disease. Circulation, 56, 1, 82-90.

\section{Re-entrant tachycardia involving concealed retrograde direct VA pathway in patients with short PR interval, normal QRS complex syndrome}

\section{E. Ward, J. Camm, and R. A. J. Spurrell Department of Cardiology, St. Bartholomew's Hospital, London}

In the short PR interval, normal QRS complex syndrome paroxysmal, regular tachycardias are usually the result of circus movement involving the atrioventricular node and a partial or complete AV nodal bypass. In two patients a different mechanism was responsible for the tachycardia.

Rapid atrial pacing or atrial premature beats resulted in minimal prolongation of the atrial to His bundle (AH) interval, consistent with the presence of a partial extranodal bypass or a rapid intranodal conduction pathway. Early atrial premature impulses resulted in closely coupled His bundle depolarisations and delay distal to the His bundle allowing the following observations: (1) Tachycardia was initiated when critical anterograde delay developed distal to the His bundle. (2) Constancy of the QRS to atrial echo time in the presence of variable infra-Hisian delay.

These two phenomena imply that the impulse returned to the atria via the ventricles through a concealed VA pathway and not via the pathway responsible for the short $P R$ interval. The $A H$ interval at the initiation of, and during, tachycardia remained short suggesting that the fast anterograde pathway continued to operate during tachycardia. Circus movement tachycardia in these patients utilised two anomalous pathways and did not include the normal AV node.
Mexiletine; effective therapy for Wolff-Parkinson-White syndrome

Simon P. Joseph, Brian Kelly, David Holt, and J. White

Middlesex Hospital and Central Medical

Establishment, Royal Air Force, London

Electrophysiological effects of mexiletine on normal and abnormal pathways of the Wolff-ParkinsonWhite syndrome were investigated in 6 patients ( 4 type $A$ and 2 type B). Four patients had bypass tracts with long anterograde and short retrograde refractory periods; one had short, and one had long refractory periods in both directions.

After intravenous mexiletine, monitored with plasma concentrations, 3 patients showed significant shortening of anterograde AV nodal refractory periods, which allowed maximum atrial pacing with 1:1 atrioventricular conduction, to rise from an average of 150 to $175 / \mathrm{min} ; 4$ patients showed significant prolongation of retrograde bypass refractory periods which decreased the maximum rate of ventricular pacing with $1: 1$ ventriculoatrial conduction from an average of 180 to $145 / \mathrm{min}$.

Mexiletine effectively suppressed the initiation of macro re-entry tachycardia in 2 of the 4 patients in whom it could be induced initially; in the other 2 the tachycardia was initiated but the cycle length was longer and alternated to terminate spontaneously after a few beats. The drug did not suppress the tachycardia in the patient with bidirectional short bypass refractory periods.

As refractory periods of two parts of the re-entry circuit change in opposite directions, mexiletine may represent ideal pharmacological therapy in selected patients.

\section{Significance of wide QRS complexes during paroxysmal reciprocating atrioventricular tachycardia (PRAVT)}

\section{E. Rowland and D. M. Krikler Royal Postgraduate Medical School, London}

During PRAVT aberrant ventricular depolarisation may not only cause diagnostic difficulty but reflect special properties of the circuit. Wide QRS complexes ( $>120 \mathrm{~ms}$ ) were seen during PRAVT in 28 of 86 patients investigated by intracardiac electrophysiological techniques. In all 5 patients with bundle-branch block during sinus rhythm the pattern persisted during the tachycardia. 
Nine patients developed tachycardia-dependent aberration which did not influence the re-entry circuit. In 10 patients the appearance or dissipation of aberration influenced the cycle length (and thus rate) of the tachycardia; when aberration occurred on the same side of the heart as an accessory pathway, the tachycardia was slowed because the circuit lengthened. In 7 aberration at the onset was the cause of the delay in the circuit that allowed reciprocation. The accessory pathway formed the anterograde limb of the circuit (antidromic tachycardia) in 4 patients, producing wide complexes. In 8 patients in whom the tachycardia reciprocated along two bypasses and did not traverse the AV node, response to conventional therapy was less good than usual.

Recognition of these patterns is important for the understanding of the mechanism as well as the therapy of the arrhythmia.

\section{Atrial fibrillation and WPW syndrome}

\section{R. W. F. Campbell, R. A. Smith, J. J. Gallagher, E. L. C. Pritchett, and A. G. Wallace \\ Duke University, North Carolina, USA}

Atrial fibrillation (AF) is reported to occur in 10 to 32 per cent of patients with WPW syndrome and may have serious consequences if atrioventricular conduction is rapid. AF leading to ventricular fibrillation (VF) seems disproportionately common in young patients who do not have other cardiac abnormalities. In this study the records of 16 patients with WPW who developed AF during electrophysiological investigation were analysed. These patients had a high incidence of preadmission VF. AF occurred (1) spontaneously during reciprocating tachycardia (RT) in 63 per cent (10 of 16), (2) during atrial pacing in RT in 19 per cent ( 3 of 16), (3) during right ventricular pacing in 25 per cent (4 of 16), and (4) from a spontaneous premature ventricular depolarisation during $R T$ in 1 patient. The mechanisms of onset of AF in these situations suggest that the accessory pathway was necessary for the initiation of AF and this may explain the high incidence of AF in the WPW syndrome. This has important therapeutic implications as ablation of retrograde function in an accessory pathway may protect the patient from the development of AF.

\section{Operative treatment of Wolff-Parkinson- White syndrome}

A. J. Camm, G. M. Rees, D. E. Ward, and

R. A. J. Spurrell

St. Bartholomew's Hospital, London
Eleven patients with the Wolff-Parkinson-White syndrome who proved refractory to medical therapy (8 patients) or who were undergoing surgery for coexisting heart disease ( 3 patients) were selected for operation. Ten patients were severely symptomatic, with re-entrant tachycardias (9 patients) and atrial fibrillation with a rapid ventricular response (5 patients).

Pre-operatively an electrophysiological study was performed to confirm that the accessory pathway (AP) was a direct atrioventricular connection and that it was utilised during the tachycardia. The location of the AP was determined by endocardial and coronary sinus catheter mapping. Eight patients had right-sided APs and 3 had left lateral APs. Apparent septal bypasses were excluded.

At surgery the ventricular epicardial surface was mapped during atrial pacing at rates sufficient to produce pre-excitation. Simultaneous atrial and ventricular epicardial atrioventricular groove mapping and, under normothermic bypass, atrial endocardial mapping, during tachycardia, precisely located the AP. Surgical section of the AP was performed by diathermy of the endocardium on the atrial side of the annulus fibrosus. Epicardial mapping was repeated and in all patients no evidence of pre-excitation was found. No significant morbidity occurred.

Follow-up for an average of 13 months (6 to 21 months) has not revealed any recurrence of preexcitation or re-entrant tachycardia in any case.

\section{Familial form of pre-excitation associated with various forms of tachy- and bradyarrhythmias: electrocardiographic pattern documented through four generations}

Per Zetterqvist, Lars Malmberg, and Hans Vallin Karolinska Hospital, Stockholm; Örebro Hospital, Örebro; and Seraphimer Hospital, Stockholm, Sweden

A short PR interval was recorded in 5 individuals from 4 generations of a family originating from northern Sweden. The pedigree data indicate an autosomal dominant mode of inheritance.

Two young family members are free from symptoms while the other 3 have suffered from various serious forms of arrhythmias in middle age. The symptomatic patients had all experienced both tachyand bradyarrhythmias in the form of atrial fibrillation or flutter alternating with progressive sinus bradycardia. One patient in addition developed AV block III with a low ventricular rate and syncope.

One patient had an electrophysiological study 
performed indicating the presence of accessory pathways between atria and His bundle (James' tract) and between His bundle and ventricular myocardium (Mahaim's tract) as the cause of the short PR interval. Corrected sinus node recovery time was prolonged.

Two sibs were treated with permanent pacemakers. Their father would also have required pacing but lived in the prepacing era.

\section{Pathology of aortic regurgitation}

M. J. Davies, I. Brooksby, G. J. Leech, J. Parker, and M. V. Braimbridge

St. George's Hospital, London, and

St. Thomas' Hospital, London

The pathology of pure aortic regurgitation was analysed in 91 patients undergoing aortic valve replacement.

In 19 cases $(20.9 \%)$ the aortic regurgitation was the result of bacterial endocarditis causing cusp perforation in a bicuspid valve ( 9 cases) or in an otherwise normal tricuspid valve (10 cases).

In 21 cases $(23 \%)$ cusp retraction resulted from rheumatic disease; only 8 cases were from United Kingdom subjects.

In 28 cases $(30.8 \%)$ the cause was either inflammatory aortic root disease (8 cases), or idiopathic aortic root dilatation (20 cases). The latter have destruction of elastic and muscle in the aortic media leading to widening of the upper margin of the aortic valve ring to which the cusps attach. Resulting reduction in cusp overlap in the closed position allows prolapse to occur. The lower margin of the ring, the one usually palpated by the surgeon, is often normal. Idiopathic aortic root dilatation ('aortopathy') is thus the commonest cause of aortic regurgitation in the United Kingdom.

In 14 cases $(15.4 \%)$ bicuspid valves were associated with severe regurgitation without bacterial endocarditis.

\section{Use of M-mode echocardiography to determine pathogenesis of aortic regurgitation}

G. J. Leech, M. J. Davies, I. Brooksby, J. Parker, and M. V. Braimbridge

St. George's Hospital, London, and

St. Thomas' Hospital, London

A separate communication has shown that primary dilatation of the aortic root is a common cause of aortic regurgitation.

Aortic root echocardiograms of 40 patients undergoing valve replacement for aortic regurgitation were reviewed independently, then correlated with surgical and histological findings.

In 17 cases with tricuspid aortic valves, where regurgitation resulted from rheumatic damage or endocarditis, cusp echoes were abnormal, but the aortic root was never dilated.

In 9 cases with bicuspid valves it was possible to show abnormal cusp echoes in only 4. However, the aortic root appeared dilated in 6.

In 14 patients the aortic valve was normal, apart from 'rolled' cusp edges in 7. The echo showed root dilatation in 10, of whom 3 had root histology showing degenerative changes in each. The remaining 4 had normal root diameter and the pathogenesis of their regurgitation remains obscure.

$M$-mode echocardiography can measure aortic root diameter at valve cusp attachment level and detects dilatation sufficient to produce regurgitation without additional cusp abnormality. Root dilatation was an unexpected finding in 67 per cent of the regurgitant bicuspid valves.

\section{Aneurysm of left ventricle secondary to bacterial endocarditis}

R. N. Sapsford, D. H. Fitchett, D. Tarin, and R. H. Anderson

Divisions Cardiovascular Disease and Pathology,

Royal Postgraduate Medical School,

Hammersmith Hospital, and Cardiothoracic

Institute, Brompton Hospital, London

Three cases of aneurysm of the left ventricular outflow tract secondary to bacterial endocarditis involving the aortic valve are described. Two cases were successfully surgically treated while the third died during apparently satisfactory medical therapy for bacterial endocarditis.

The aneurysms occurred in the junctional area between the mitral and aortic valves, bulging upwards between the left atrium and aorta. There was no evidence of active infection in either the cavity or wall of the true aneurysm. There was a perforation or detachment of the right aortic cusp directly above the orifice of the aneurysms.

A likely pathogenetic mechanism is that the infected regurgitant blood striking the aorto-mitral continuity, set up a jet lesion and subsequent weakness of the wall. Other possibilities include em- 
bolism and an intrinsic congenital weakness of the area.

All patients previously described have died from perforation of the aneurysm and tamponade. Though there were no suggestive clinical features in our patients, both echocardiography and angiography demonstrated the aneurysm in one of the cases.

In view of the high risk of rupture, the diagnosis should be sought in all patients with bacterial endocarditis of the aortic valve, particularly when this has produced significant aortic regurgitation.

\section{Inotropic stimulation without detriment to subendocardial perfusion in patients soon after cardiac surgery}

\section{A. D. Malcolm, D. J. Coltart, F. L. Rosenfeldt, and B. T. Williams \\ Departments of Cardiology and Cardiovascular Surgery, The Rayne Institute, St. Thomas' Hospital, London}

The ratio of the diastolic pressure-time index to the tension-time index (DPTI/TTI) reflects adequacy of subendocardial perfusion. We have examined the effects of 3 inotropic agents on DPTI/TTI in patients 12 to 48 hours after cardiopulmonary bypass. Inotropic effect was quantified by indices derived from simultaneous arterial pressure and aortic flow measurements, the latter obtained with an extractable electromagnetic probe.

Isoprenaline ( 8 patients) was infused intravenously at $0.01,0.02$, and $0.04 \mu \mathrm{g} / \mathrm{kg}$ per minute. Adrenaline ( 5 patients) or noradrenaline (5 patients) was infused intravenously at $0.03,0.06,0.12$, and $0.24 \mu \mathrm{g} / \mathrm{kg}$ per minute. Results are group mean percentage changes from predrug baseline with successive incremental doses.

Isoprenaline produced a fall of 15,20 , and 36 per cent in DPTI/TTI, with corresponding increases in stroke work of 12,18 , and 21 per cent, and of peak ejection power of 24,35, and 61 per cent. Adrenaline altered DPTI/TTI by $+2,-2,-13$, and -33 per cent, stroke work by $+14,+21,+60$, and +89 per cent, and peak ejection power by +21 , $+33,+88$, and +141 per cent. Noradrenaline, however, produced changes in DPTI/TTI of only $-6,-5,-2$, and -1 per cent; correspondingly, stroke work increased 5, 23, 57, and 91 per cent and peak ejection power $2,27,68$, and 113 per cent.

Inotropic augmentation can be achieved without impairment of subendocardial perfusion, as demonstrated with noradrenaline.

\section{Role of angiotensin II in development of peripheral vasoconstriction during cardiopulmonary bypass}

\author{
K. M. Taylor, J. Brannan, W. H. Bain, \\ P. K. Caves, and J. J. Morton \\ University Department of Cardiac Surgery, \\ Royal Infirmary and M.R.C. Blood Pressure \\ Unit, Western Infirmary, Glasgow
}

Increased peripheral vasoconstriction, occurring during and for the first few hours after cardiopulmonary bypass (CPB), is a well-recognised but poorly understood phenomenon. Among other possible aetiological factors, it has been suggested that the renin-angiotension system and, in particular, the powerful vasopressor angiotensin II (AII), may be involved.

Plasma AII levels (normal $5-35 \mathrm{pg} / \mathrm{ml}$ ) have been measured by radioimmunoassay in 12 patients during and after non-pulsatile CPB and in 6 closed mitral valvotomy controls. Plasma AII levels rose during operation to around $60 \mathrm{pg} / \mathrm{ml}$ in the control patients and returned towards normal postoperatively. In the bypass patients, AII levels rose conspicuously during $\mathrm{CPB}$ to a mean end-bypass $\mathrm{AII}=247 \mathrm{pg} / \mathrm{ml} \pm 35 \mathrm{SEM}$ and remained high at 2 hours post-CPB (AII $=223 \pm 22$ SEM). Around 4 hours post-CPB, AII levels fell rapidly and remained around normal values at 24 hours after operation.

An attempt was made to relate the rise in AII levels during $C P B$ to the change in peripheral vascular resistance (PVR). Plasma AII levels and calculation of PVR were obtained in 16 patients at the start and end of the period of CPB. The rise in AII levels was correlated with the change in PVR for each patient, and a highly significant correlation obtained $(r=0.9101)$.

We conclude that the increase in peripheral vascular resistance which occurs during nonpulsatile CPB is directly related to increase in the plasma level of angiotensin II.

\section{Yield of coronary arteriography before aortic valve replacement}

J. Watkins, N. Conway, I. Hyde, J. L. Monro, and J. K. Ross

Wessex Regional Cardiac and Thoracic Centre, Oakley Road, Southampton

Of 270 patients undergoing aortic valve replacement between 1972 and $1977,138(51 \%)$ had selective coronary arteriography beforehand, 113 for angina, 
and 25 because of previous myocardial infarction or electrocardiographic suspicion of coronary artery disease (CAD). Only $30(22 \%)$ were found to have significant disease (one or more stenoses of at least $50 \%$ ). This figure is lower than previously reported. The presence of CAD was unrelated to age (except in the angina-free group) and only 2 of the patients were female. CAD was twice as likely with dominantly stenotic, rather than dominantly regurgitant, aortic lesions.

The patients having selective coronary arteriography were compared with the remaining 132 who did not, again divided into those with, and those without, angina. Hospital deaths after surgery were twice as frequent in the unstudied group; and while the total mortality was low $(9$, or $3 \%$ overall), seven of these were related to a coronary problem, whether of cannulation at operation or of myocardial damage.

Despite the low yield of positive findings, and the obvious fallacy of assuming coronary deaths to be necessarily preventable, coronary arteriography seems advisable as a routine when aortic valve replacement is undertaken using coronary perfusion.

\section{Cardiovascular effects of weight reduction after intestinal shunt operation for obesity}

\author{
U. Freyschuss, L. Backman, D. Hallberg, \\ and A. Melcher \\ The Departments of Clinical Physiology, \\ Karolinska Hospital and Serafimer Hospital, \\ Stockholm, Sweden
}

Cardiovascular performance has been studied in 22 patients with gross obesity before and after operation for weight reduction (jejuno-ileostomy). The investigations have, on both occasions, included heart and blood volume measurements, right heart and arterial catheterisations with determinations of cardiac output, oxygen consumption, and intracardiac and intravascular pressure both at rest and during exercise.

Body weight was reduced from a mean of 146 to $88 \mathrm{~kg}$ (104 to $39 \%$ overweight) during a 2-year period. The weight reduction was associated with loss of metabolic active mass and a decrease of oxygen consumption, blood and heart volume, and cardiac output. Pulmonary vascular resistance and the filling pressures of the heart remained high, while systemic vascular resistance was normalised and left ventricular work was reduced.

The favourable effects on the systemic circulation imply that improved cardiovascular function may be added to the indications for operative therapy in extreme obesity.

\section{Mechanism of influence of $P R$ interval on first heart sound}

\author{
N. Brooks, G. Leech, and A. Leatham \\ St. George's Hospital, London
}

The intensity of the first heart sound is known to vary with the $P R$ interval and the position of the atrioventricular valve cusps at the onset of ventricular contraction. However, the exact mechanism whereby a loud sound is produced when the valve is wide open and a soft sound when nearly closed remains speculative, and the only previous studies in man have been on patients with heart block.

We have studied 67 normal subjects, using highspeed echophonocardiography to determine the influence of $P R$ interval on AV valve closure timing relative to the onset of systole, and the loudness of the first heart sound.

With a long PR interval, valve closure takes place relatively soon after the $Q$ wave of the electrocardiogram, during the initial slow rising portion of the ventricular pressure pulse, and the first heart sound is soft. When the PR interval is shorter, valve closure is later, when pressure is rising much more rapidly, and the first sound is louder.

Some interesting differences were found between the effect of left atrial and right atrial contraction on valve movement, explaining the longer gap between the mitral and tricuspid components of the first sound than between the onset of left and right ventricular contraction.

\section{Significance of epicardial fat layer in radiological evaluation of heart disease}

\section{Alfred Szamosi \\ Karolinska Sjukhuset, Stockholm}

The heart has traditionally been considered a radiologically homogeneous organ. Statements concerning the size of individual heart chambers has been based on the shape of the heart, i.e. on the outer contours. Slowly accumulating but significant improvements in radiographic technique make it necessary to reconsider this view. The epicardial fat and other factors are able to generate low level contrasts within the borders of the heart. The density differences that arise are spatially related to certain cardiac structures, which thus can be perceived and recognised. The appearance on plain chest film of the intrapericardial part of the ascending aorta, left ventricle and atria will be shown on slides. 
Remodelling of membranous septum throughout life and its relevance to defective ventricular septation

S. P. Allwork and R. H. Anderson Department of Surgery, Royal Postgraduate Medical School, and Department of Paediatrics, Cardiothoracic Institute, Brompton Hospital

Interventricular communication accounts for onefifth of all congenital cardiac anomalies, and more than three-quarters of these have been described as 'membranous'. Ventriculoatrial communication through the membranous part of the septum is, however, rare. This disparity of incidence of malformation of the two components of this structure prompted us to examine the development of the membranous septum in 25 hearts aged from 15 weeks of gestation to the ninth decade of adult life.

The atrioventricular component was evident in all the hearts, but the interventricular component was present in only 1 of 5 fetuses and in only 2 of the 10 neonatal hearts. In the other neonatal hearts, there was no fibrous tissue between the medial tricuspid leaflet and the muscular ventricular septum. Instead, the area occupied by the interventricular component in the adult heart was filled by the atrioventricular bundle (bundle of $\mathrm{His)}$ and by muscle. The medial tricuspid leaflet was attached to this muscle along most of its length. In adult hearts, the medial tricuspid leaflet was in every case attached to the interventricular membranous septum by secondary chordae tendineae.

In conclusion, it is evident that formation of the interventricular component of the membranous septum is a late event, occurring in most instances in childhood. It is equally evident, therefore, that defects in the area of the membranous septum are not related to absence of this septum, and that the term 'membranous septal defect' is a misnomer. 